\title{
The use of $\mathrm{N}^{\wedge} \mathrm{N}$ ligands as an alternative strategy for the sol-gel synthesis of visible-light activated titanias
}

Received 00th January 20xx, Accepted 00th January 20xx

DOI: $10.1039 / \times 0 x \times 00000 x$

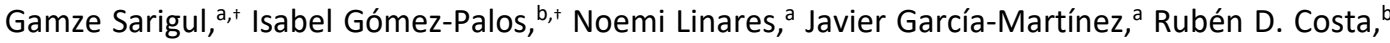 \\ Elena Serrano, $*$ a
}

This work presents the first biphasic brookite-rutile organotitanias, TiO2(B,R)-Phen, synthesized by sol-gel, using mild conditions and 1,10-phenanthroline (Phen) as crystal modifier and as a source of intermediate N2p states. Phen is able to coordinate to the Ti(IV) atom of the titanium alkoxide precursor, tetrabutyl orthotitanate (TBOT), forming an organotitania precursor that leads to a binary brookite-rutile structure, instead of the typical anatase. Different from the nitrogen-doped titanias, in which the $\mathrm{N} 2 \mathrm{p}$ levels are due to the presence of $\mathrm{N}$ atoms in the $\mathrm{O}$ lattice position of the titania crystal, the coordination between the Ti atom of the titania precursor and the Phen is maintained during the whole synthetic process, being the responsible for the intermediate N2p states related to Ti-N bonds in the final mate-rials, which is key to activate the photocatalysis behavior under visible light. Both features allow simultaneously reduc-ing charge recombination rate and enhancing photo-induced electron transfer in the visible range. Indeed, a 10-fold increase in the photocatalytic rate constant along with enhanced stability for the degradation of cationic dyes in aqueous solutions under visible light were noted in stark comparison to reference titanias. The photocatalyst mechanism consists in the self-degradation of the dyes, while the enhanced photoactivity results from a combination of the binary brookite-rutile structure and the blue absorption Ti- $\mathrm{N}$ states. As such, this work presents a unique synthesis strategy to obtain biphasic brookite-rutile organotitanias bearing Ti- $\mathrm{N}$ bonds that leads to superior photocatalytic degradation activity of pollutants in aqueous solutions using visible light.

\section{Introduction}

The main text of the article should appear here with headings as appropriate. Anatase titanium dioxide, $\mathrm{TiO}_{2}(\mathrm{~A})$, is the most widely used photocatalyst due to its chemical stability, biocompatibility, non-toxicity, and competitive cost. $^{1}$ In general, the enhancement of the photoactivity of titania-based materials has been focused on: surface modification, doping, photosensitization, and/or coupling semiconductors. ${ }^{2}$ Among the many factors influencing its efficiency as a photocatalyst, electron-hole recombination is the most critical, while its modification to make it active under visible light is key towards a wide range of applications.

In this context, the use of nanoparticles featuring a mixture of crystalline titania phases, both biphasic and triphasic, is considered one of the most promising strategies to reduce electron-hole recombination, because of their higher photocatalytic activity compared to their one phase counterparts under UV light. ${ }^{2,3}$ However, it is still a major challenge due to the lack of efficient synthesis procedures to fine control the size and distribution of the titania phases. ${ }^{4-6}$ For instance, the improved photocatalytic activity of P25 $(80 \%$ anatase, $20 \%$ rutile) is attributed to the reduced recombination

\footnotetext{
Universidad de Alicante, Departamento de Química Inorgánica, Laboratorio de Nanotecnología Molecular, Ctra. San Vicente-Alicante s/n, E-03690 Alicante, Spain. www.nanomol.es.

b. IMDEA Materials Institute, Calle Eric Kandel 2, E-28906 Getafe, Madrid, Spain + G.S. and I.G.-P. These authors contributed equally

Electronic Supplementary Information (ESI) available: [details of any supplementary information available should be included here]. See DOI: 10.1039/x0xx00000x
}

rate within the anatase phase, which is due to the efficient charge transfer from the anatase to the rutile phases at the junction formed between both crystalline lattices. A major limitation of the synthesis of mixed titania phases is the need to use either basic or acidic conditions as well as high temperatures. $3,4,7,8$ Moreover, although brookite is now recognized as a photoactive phase, in some cases showing enhanced performance over both anatase or rutile, 7,9 the synthesis of brookite nanoparticles under controlled conditions still represents a major milestone in the field. ${ }^{10,11}$ Indeed, only a handful number of reports describe the synthesis of biphasic brookite/rutile titania nanocrystals. ${ }^{7,12-16}$

A leading strategy to improve both, the electron-hole recombination and the photocatalytic activity under visible light, is the use of nitrogen-doped titanias. ${ }^{2,17,18}$ More specifically, heterojunctions based on $\mathrm{N}$-doped titanias consisting on biphasic and/or triphasic anatase-rutile-brookite phases have demonstrated both efficient electron-hole separation and superior visible light photocatalytic activity. ${ }^{5,19-}$ ${ }^{21}$ As alternative, a few groups have focused on the sol-gel synthesis of photocatalysts using organic ligands. They are able to react with the alkoxide groups of non-silicate metal alkoxides forming new molecular $\mathrm{M}(\mathrm{OR})_{\mathrm{x}}(\mathrm{L})_{\mathrm{y}}$ precursors, which exhibit different molecular structures and reactivity. ${ }^{22-25}$ The integration of these complexes influences the formation of the crystalline phase in titania-based materials. ${ }^{19,24,26-28}$ Shubert et al. ${ }^{24}$ reported the synthesis of aminoacid functionalizedtitanium and zirconium alkoxides for the sol-gel synthesis of titanate or zirconate materials, in which different anatase-torutile ratios were obtained depending on the precursor and synthesis conditions used. 


\section{Unmodified titanias}

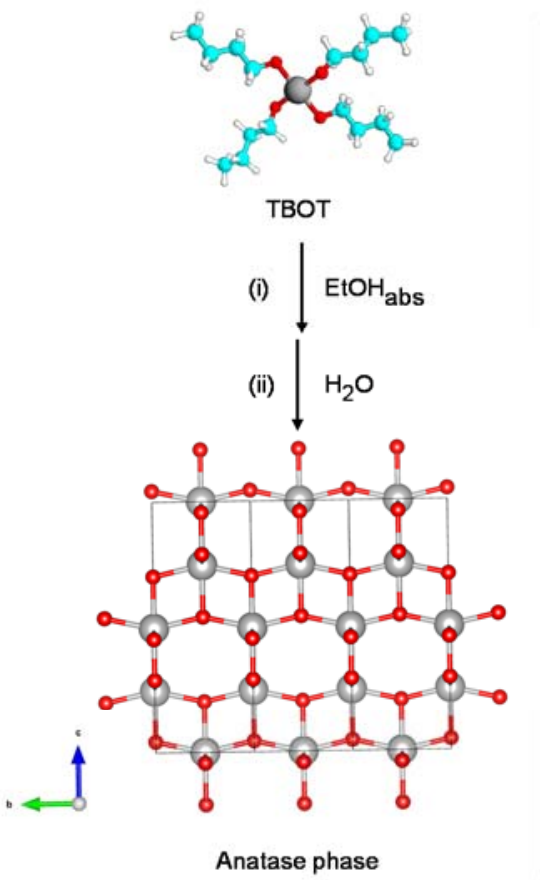

$\mathrm{TiO}_{2}(\mathrm{~A})$
Hybrid $\mathrm{TiO}_{2}$-Phen organotitanias with biphasic brookite-rutile structure

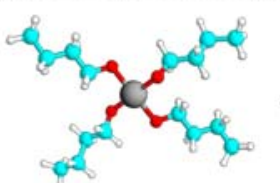

TBOT

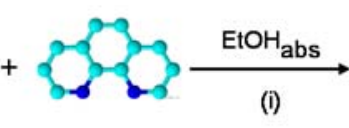

Phen

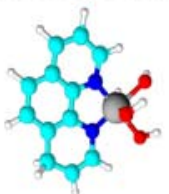

Organotitania precursor

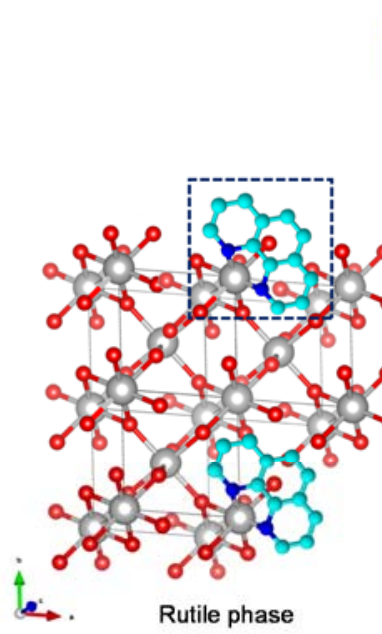

(ii) $\downarrow \mathrm{H}_{2} \mathrm{O}$
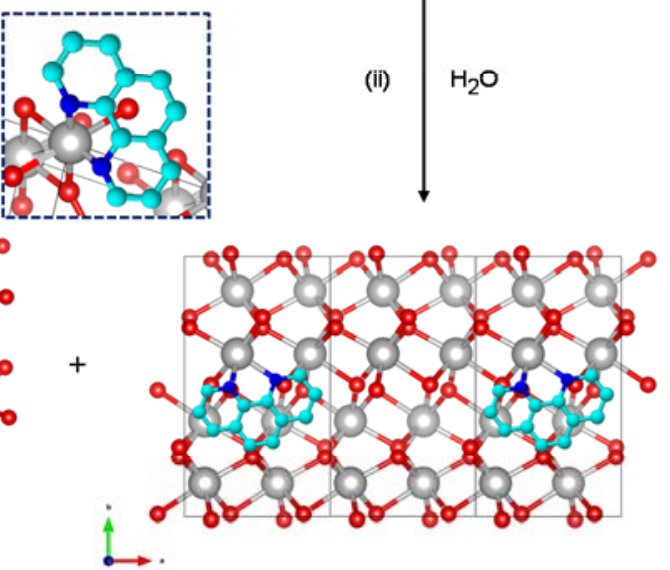

Brookite phase

$\mathrm{TiO}_{2}(\mathrm{~B}, \mathrm{R})-\mathrm{Phen}$

(i) Organotitania precursor ( $\mathrm{Ti}^{\mathrm{V}} \mathrm{V}$ complex) formation

(ii) Hydrolysis at RT + crystallization at $100^{\circ} \mathrm{C}$

(i) TBOT dissolution in absolute ethanol

(ii) Hydrolysis at RT + crystallization at $100^{\circ} \mathrm{C}$ $\bigcirc \mathrm{Ti} \odot \mathrm{COO} \mathrm{N} \bigcirc \mathrm{H}$

Scheme 1. (Left) Synthesis of the unmodified anatase titania, TiO2(A), starting from tetrabutyl orthotitanate (TBOT). ${ }^{29-31}$ (Right) Schematic illustration of the synthesis of the hybrid $\mathrm{TiO} 2(\mathrm{~B}, \mathrm{R})$-Phen organotitanias with binary brookite/rutile crystalline phases, starting from TBOT and 1,10-phenanthroline (Phen), using the same conditions, and the proposed $\mathrm{TiO} 2(\mathrm{~B}, \mathrm{R})-$ Phen structure.

The integration of these complexes influences the formation of the crystalline phase in titania-based materials. ${ }^{19,24,26-28}$ Shubert et al. ${ }^{24}$ reported the synthesis of aminoacid functionalizedtitanium and zirconium alkoxides for the sol-gel synthesis of titanate or zirconate materials, in which different anatase-torutile ratios were obtained depending on the precursor and synthesis conditions used. Reddy et al. ${ }^{19}$ reported the preparation of $\mathrm{N}$-doped titanias with a variable phase composition by hydrothermal treatment of sodium titanates in the presence of aqueous urea. Kakihana et al. ${ }^{26-28}$ selectively synthesized pure and mixed titania polymorphs by hydrothermal treatment of water-soluble titanium complexes using nitrogen-containing additives both at acidic and strongly basic $\mathrm{pH}$. They were able to synthesize rod-like nanosized particles of single-phase brookite from the titanium-glycolate complex, in the presence of excess $\mathrm{NH}_{3}$ aqueous solution or ethylenediamine. ${ }^{27}$

Herein, we report, the sol-gel synthesis of biphasic brookiterutile (ca. 50:50) organotitanias, $\mathrm{TiO}_{2}(\mathrm{~B}, \mathrm{R})$-Phen, using 1,10phenanthroline (Phen) as both, crystal modifier and as the source of intermediate $\mathrm{N} 2 \mathrm{p}$ states, to simultaneously reduce charge recombination rate and enhance the photo-induced electron transfer in the visible range, respectively.

Phen exhibits a versatile chelating character ${ }^{22}$ and good electron transport/hole blocking features. ${ }^{32-34}$ For instance, physical blends of titania nanoroads with Phen promotes the reduction of the recombination rate at the interface, significantly enhancing the efficiency in inverted organic solar cells (OSC). ${ }^{33}$

In view of the above-mentioned, we took advantage of our expertise in the in-situ incorporation of organic and coordination compounds into the anatase structure ${ }^{29-31,35}$ to investigate the effect of incorporating Phen into the titania structure during their sol-gel synthesis, using mild conditions and low temperatures. Two aspects warrant a significant impact of the work at hand. First, we rationalize how the use of Phen as crystal modifier selectively induce the crystalline phase of the hybrid titanias, once the $\mathrm{Ti} \cdots \mathrm{N}$ bond is formed through the coordination of Phen to the Ti(IV) atom of the titanium alkoxide precursor, $\mathrm{Ti}(\mathrm{OR})_{4}$. This method leads to a fine control of the formation of biphasic brookite-rutile titania - Scheme 1, right. To the best of our knowledge, this represents the first sol-gel synthesis of biphasic brookite-rutile titanias using mild 
conditions with functional-organic compounds as crystal modifiers, achieving a tunable control of their crystalline structure. As a reference, if Phen is not added, sol-gel synthesis of titania leads to anatase phase -Scheme 1 , left, while brookite is a subproduct of the reaction in acidic conditions. ${ }^{6}$

Finally, $\mathrm{TiO}_{2}(\mathrm{~B}, \mathrm{R})$-Phen materials shows a 10 -fold higher first-order photocatalytic rate activity along with enhanced stability (4 catalytic cycles) compared to anatase and anataserutile titanias. This study was carried out with the degradation of cationic dyes, i.e., rhodamine $6 \mathrm{G}$, rhodamine $\mathrm{B}$, and methylene blue, under visible light (liquid cut-off filter $>400$ $\mathrm{nm}$ ) in aqueous solutions. This is attributed to i) the presence of brookite phase promoting self-degradation dye mechanism, ii) a reduced electron-hole recombination due to the presence of rutile phase and electron-deficient $\mathrm{Ti}-\mathrm{N}$ bonds, and iii) the enhanced photoactivity in the blue region of the visible spectrum due to the energetic levels of $\mathrm{N}$ coming from the $\mathrm{Ti}$ bonds in the titanias. ${ }^{32-34}$ As such, this work presents a unique synthesis strategy to obtain biphasic brookite-rutile organotitanias bearing $\mathrm{Ti}-\mathrm{N}$ bonds that leads to superior photocatalytic degradation activity of pollutants in aqueous solutions using visible light.

\section{Results and discussion}

\section{Synthesis and characterization of hybrid titania-phenanthroline organotitanias}

The synthesis of the hybrid $\mathrm{TiO}_{2}(\mathrm{~B}, \mathrm{R})$-Phen organotitanias was carried out following our previously described methodology. ${ }^{29-}$ ${ }^{31}$ First, a complex between the titania precursor, in this case, tetrabutyl orthotitanate (TBOT), and Phen was directly synthesized in absolute ethanol at room temperature - Scheme $1, \mathrm{i}$, right. Second, the TBOT-Phen complex was the organotitania precursor for the synthesis of the $\mathrm{TiO}_{2}(\mathrm{~B}, \mathrm{R})$-Phen by its hydrolysis at room temperature and further crystallization at $100{ }^{\circ} \mathrm{C}-$ Scheme $1, \mathrm{ii}$, right. The direct reaction of TBOT with Phen led to a clear solution. However, although the TBOT-Phen complex remains stable in absolute ethanol even after several days, the isolation of single crystals for their further single crystal X-ray diffraction analysis was unsuccessful. This was expected as the TBOT hydrolyses at RT once the solvent is evaporated. Hence, we performed NMR analysis by directly mixing TBOT and Phen in deuterated DMSO - Fig. S1. The shift displacements observed in ${ }^{1} \mathrm{H}$ and ${ }^{13} \mathrm{C}$ NMR spectra indicate that this complex is formed through the coordination of the imine groups of the Phen with the titanium atom of the ТВОТ. This is in line with the absence of absolute ethanol and with previous observations for similar Ti(IV)-Phen complexes containing ethoxy ligands. ${ }^{36}$ Thus, the effective incorporation of the coordinated Phen in the final material was achieved, as supported by solid-state ${ }^{13} \mathrm{C}$ and ${ }^{15} \mathrm{~N}$ NMR measurements of the hybrid $\mathrm{TiO}_{2}(\mathrm{~B}, \mathrm{R})$-Phen organotitanias - Fig. 1. Importantly, the ${ }^{13} \mathrm{C}$ NMR signals 1 and 2 of the Phen - i.e., $152.3 \mathrm{ppm} ;-\mathrm{CH}=$ groups directly bonded to the $\mathrm{N}$ atom - in $\mathrm{TiO}_{2}(\mathrm{~B}, \mathrm{R})$-Phen are slightly displaced with respect to those corresponding to both, the uncoordinated Phen and the physical blend of an
Table 1 Phenanthroline incorporation into the hybrid $\mathrm{TiO}_{2}(\mathrm{~B}, \mathrm{R})$-Phen, their phase composition, crystalline domains, and textural parameters as a function of the crystallization time at $100^{\circ} \mathrm{C}$.

\begin{tabular}{|c|c|c|c|c|c|c|c|c|}
\hline \multirow[b]{2}{*}{$\begin{array}{l}\mathrm{t}_{\mathrm{c}}{ }^{a} \\
\text { (h) }\end{array}$} & \multirow{2}{*}{$\begin{array}{l}\text { Phen }^{b} \\
\text { (wt\%) }\end{array}$} & \multicolumn{2}{|c|}{ Rutile $^{c}$} & \multicolumn{2}{|c|}{ Brookite $^{c}$} & \multirow[b]{2}{*}{$\mathrm{B} / \mathrm{R}^{d}$} & \multirow{2}{*}{$\begin{array}{c}\mathrm{S}_{\mathrm{BET} T}{ }^{e} \\
\left(\mathrm{~m}^{2} / \mathrm{g}\right)\end{array}$} & \multirow{2}{*}{$\begin{array}{c}V_{p}{ }^{e} \\
\left(\mathrm{~cm}^{3} / g\right)\end{array}$} \\
\hline & & $\begin{array}{c}d_{\mathrm{R}, 110} \\
(\AA ̊)\end{array}$ & $\begin{array}{c}D \\
(\mathrm{~nm})\end{array}$ & $\begin{array}{c}d_{\mathrm{B}, 121} \\
(\AA ̊)\end{array}$ & $\begin{array}{c}D \\
(\mathrm{~nm})\end{array}$ & & & \\
\hline 0 & 14.4 & n.c. & n.c. & n.c. & n.c. & n.c. & 97 & 0.09 \\
\hline 6 & 12.2 & n.c. & n.c. & n.c. & n.c. & n.c. & 250 & 0.16 \\
\hline 12 & 12.9 & n.c. & n.c. & n.c. & n.c. & n.c. & 105 & 0.27 \\
\hline 18 & 12.3 & $*$ & $*$ & $*$ & $*$ & $*$ & 350 & 0.23 \\
\hline 24 & 11.8 & 3.22 & 22.2 & 2.88 & 15.2 & $77 / 23$ & 171 & 0.17 \\
\hline 36 & 8.4 & 3.22 & 21.5 & 2.88 & 19.5 & $42 / 58$ & 158 & 0.22 \\
\hline 48 & 3.0 & 3.22 & 25.7 & 2.88 & 15.9 & $62 / 38$ & 122 & 0.24 \\
\hline
\end{tabular}

${ }^{a}$ Crystallization time at $100{ }^{\circ} \mathrm{C} .{ }^{b}$ Phen incorporation in the $\mathrm{TiO}_{2}(\mathrm{~B}, \mathrm{R})-\mathrm{Phen}$ determined by TG. ${ }^{c}$ Lattice spacing $(d)$ and crystalline domain size $(D)$ of the rutile (R) and brookite (B) phases in the hybrid $\mathrm{TiO}_{2}(\mathrm{~B}, \mathrm{R})$-Phen. ${ }^{d}$ Weight fractions of $R$ and $B$ in the crystalline phases of titania 37,38 . ${ }^{e}$ BET surface area ( $\left.\mathrm{S}_{\mathrm{BET}}\right)$ and total pore volume $\left(\mathrm{V}_{\mathrm{p}}\right)$ from $\mathrm{N}_{2}$ adsorption/desorption isotherms at $77 \mathrm{~K} .{ }^{*}$ Peaks are too small as to be quantified.
A

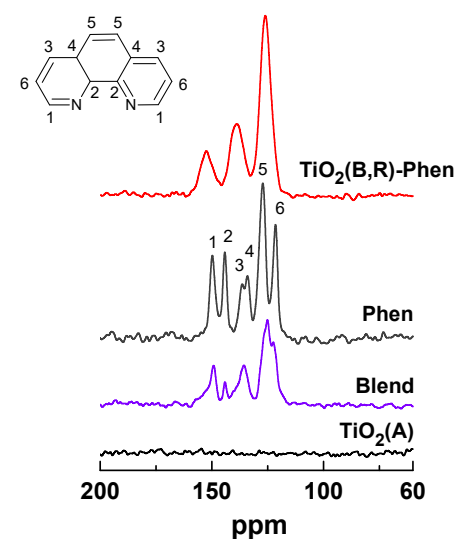

B

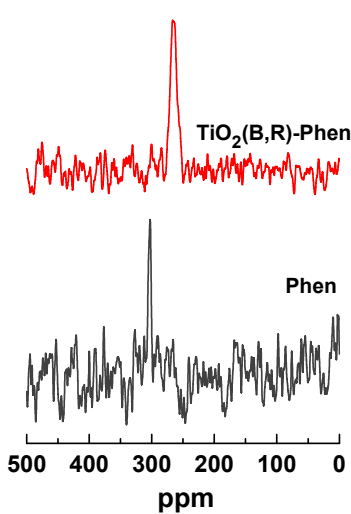

Fig. 1 Solid ${ }^{13} \mathrm{C}(A)$ and ${ }^{15} \mathrm{~N}$ (B) $N M R$ spectra of the hybrid $\mathrm{TiO}_{2}(B, R)$-Phen as compared to the spectra of Phen-free titania, $\mathrm{TiO}_{2}(\mathrm{~A})$ sample, a physical blend of $\mathrm{TiO}_{2}(\mathrm{~A})$ with 12 wt\% Phen (Blend), and the phenanthroline alone (Phen).

unmodified titania with Phen - Fig. $1 \mathrm{~A}$. In addition, the ${ }^{15} \mathrm{~N}$ chemical shift at ca. $265 \mathrm{ppm}$ in $\mathrm{TiO}_{2}(\mathrm{~B}, \mathrm{R})$-Phen indicates the presence of imino nitrogens - Fig. 1B. ${ }^{39}$ This is a clear indication of the $\mathrm{Ti} \cdots \mathrm{N}$ coordination in the hybrid material, as shown in Scheme 1.

The incorporation of Phen into the hybrid $\mathrm{TiO}_{2}(\mathrm{~B}, \mathrm{R})$-Phen materials was further analyzed by $\mathrm{X}$-ray photoelectron spectroscopy (XPS), infrared spectroscopy (IR), and TG measurements. Fig. $2 \mathrm{~A}$ shows that the amount of Phen incorporated remains almost constant up to $18 \mathrm{~h}$ at $100{ }^{\circ} \mathrm{C}$. Once the crystallization starts, the percentage of Phen in the samples decreases as the crystallinity of the titanias increases see Table 1 and Fig. 2C. Indeed, no diffraction peaks appeared in the XRD diffractograms until $24 \mathrm{~h}$ of crystallization - Fig. $2 \mathrm{C}$. This contrast with the faster crystallization of the unmodified titania synthesized without Phen under the same conditions $\mathrm{TiO}_{2}$ (A) sample-, where the characteristic XRD peaks appear after $6 \mathrm{~h}$ of crystallization - Fig. S2. ${ }^{30}$. 
A

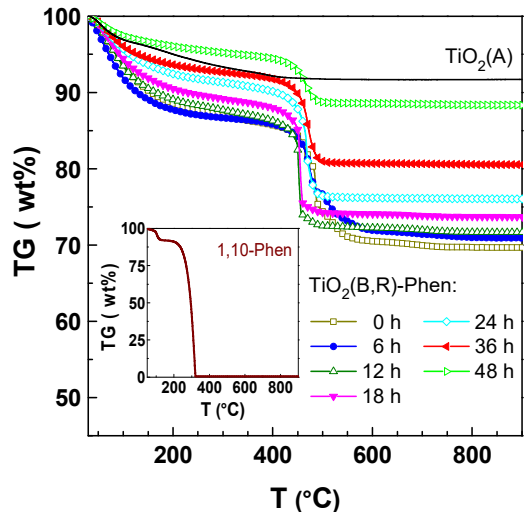

D

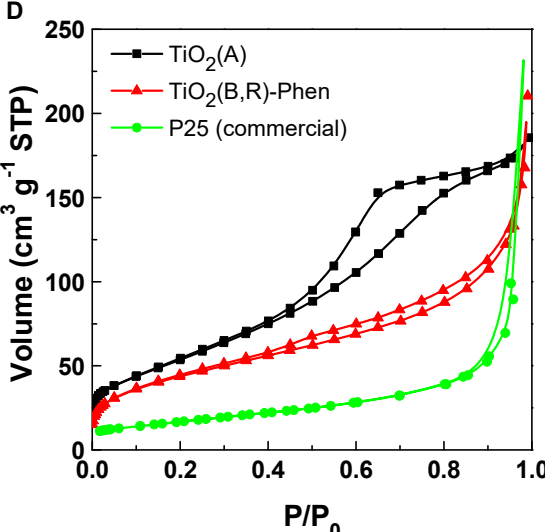

B

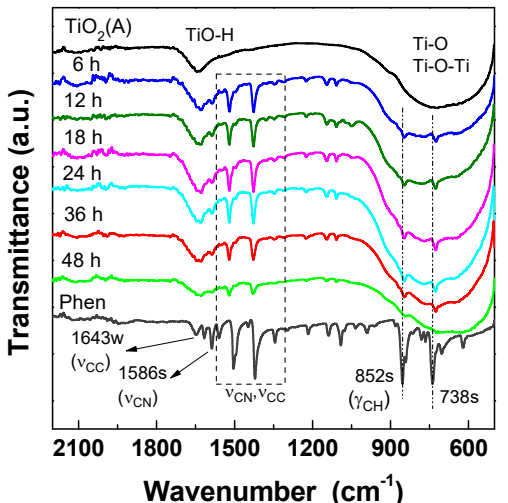

$E$

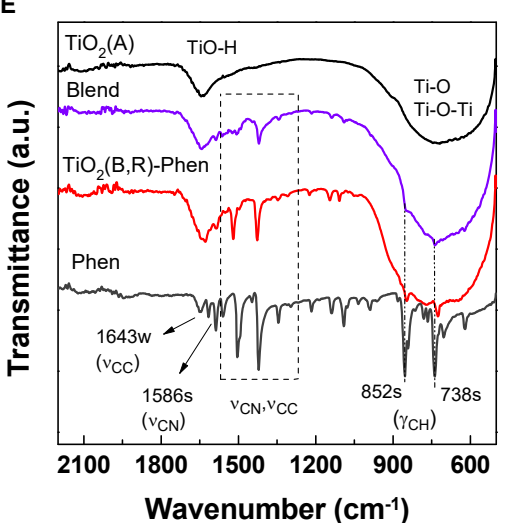

C

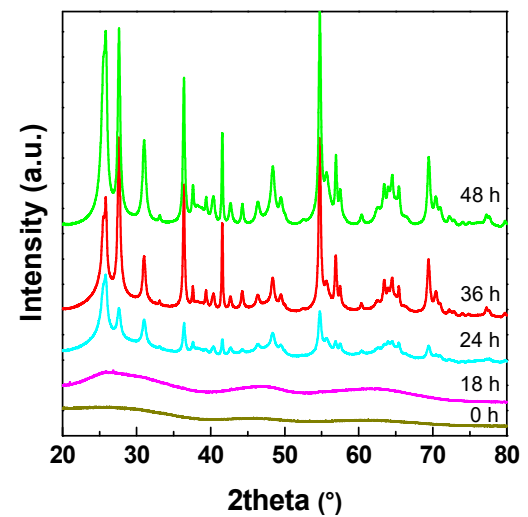

$\mathbf{F}$

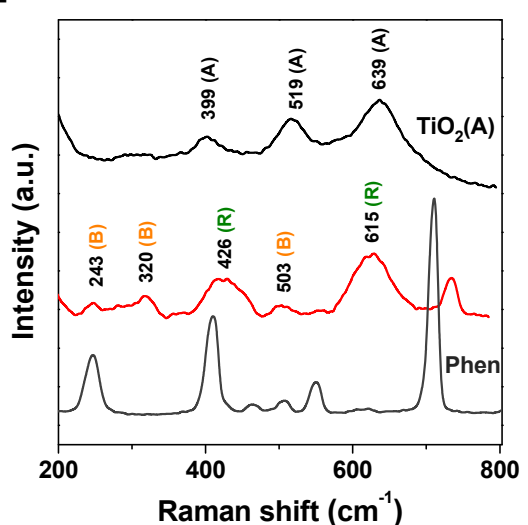

Fig. 2 (Top) Characterization of the hybrid $\mathrm{TiO}_{2}(\mathrm{~B}, \mathrm{R})$-Phen as a function of the crystallization time at 100 ㅇ: (A) TG curves, (B) FTIR spectra, and (C) XRD patterns. Data for Phen-free titania $-\mathrm{TiO}_{2}(\mathrm{~A})$-, and the phenanthroline alone -Phen - have been included for comparison purposes. (Bottom) Characterization of the hybrid TiO ${ }_{2}(\mathrm{~B}, \mathrm{R})$ - $\mathrm{Phen}$ (crystallization time $36 \mathrm{~h}$, in red) in comparison with the reference materials $\mathrm{TiO}_{2}(\mathrm{~A})$, Phen, and a physical blend of $\mathrm{TiO}_{2}(\mathrm{~A})$ with 12 wt\% Phen - Blend: (D) $\mathrm{N}_{2}$ adsorption/desorption isotherms at $77 \mathrm{~K}$, (E) FTIR spectra, and (F) Raman spectra (F).

In addition, the thermal degradation of Phen is delayed due to their incorporation into the titania structure - see inset in Fig. $2 \mathrm{~A}$. Hence, the slower crystallization rate of $\mathrm{TiO}_{2}(\mathrm{~B}, \mathrm{R})$-Phen in comparison to the unmodified titania is attributed to the incorporation of the Phen into the titania structure through their coordination with the $\mathrm{Ti}$ atom of the TBOT precursor, which clearly interferes with the formation of the crystalline structure, as discussed below.

The reduction in the phenanthroline content with crystallization time is accompanied by a decrease in the intensity of the FTIR bands assigned to Phen - Fig. 2B. FTIR spectra of Phen-free $\mathrm{TiO}_{2}$ shows a broad band between 400 and $800 \mathrm{~cm}^{-1}$, which is ascribed to the strong stretching vibrations of the $\mathrm{Ti}-\mathrm{O}$ and $\mathrm{Ti}-\mathrm{O}-\mathrm{Ti}$ bonds, sample $\mathrm{TiO}_{2}(\mathrm{~A}) \cdot{ }^{40}$ Characteristic vibrations of the Phen heterocycle are observed in two frequency ranges, namely $1300-1650 \mathrm{~cm}^{-1}$ (related to the $\mathrm{C}-\mathrm{C}$ and $\mathrm{C}-\mathrm{N}$ stretching vibrations) and $700-900 \mathrm{~cm}^{-1}$ (related to the hydrogen atoms on the heterocyclic rings). ${ }^{41-43}$ The $\mathrm{C}-\mathrm{C}$ absorption peak of Phen at $c a .1643 \mathrm{~cm}^{-1}$ overlaps with the binding vibration of $\mathrm{H}-\mathrm{O}$ bond from the terminal groups in the $\mathrm{TiO}_{2}(\mathrm{~A})$, which hamper the analysis of this band. Despite the overlapping of these bands, the energy of the ring modes (vCC and $\mathrm{vCN}$ ) of Phen in the $1300-1650 \mathrm{~cm}^{-1}$ region slightly shifts after their complexation with the Ti(IV) atom of the titania, as previously observed for other transition metal-Phen complexes. ${ }^{44,45}$ In the low energy region, the two strong bands of uncoordinated Phen at 738 and $854 \mathrm{~cm}^{-1}$ are related to the out of plane motion of the hydrogen atoms on the heterocyclic rings and on the center ring, respectively - Fig. 2B,E, Phen curve, grey bottom line. ${ }^{43}$ The former $\left(738 \mathrm{~cm}^{-1}\right)$ decreases in frequency upon coordination, appearing as a strong band at 725 $\mathrm{cm}^{-1}$ in the $\mathrm{TiO}_{2}(\mathrm{~B}, \mathrm{R})$-Phen spectra. Moreover, their frequency is not significantly affected by the crystallization time - Fig. 2B. As expected, the energy of this band remains virtually the same in the sample prepared by physically blending of the control titania with Phen, as compared to the uncoordinated Phen - Fig. $2 \mathrm{E}$. Finally, the $855 \mathrm{~cm}^{-1}$ vibration is less affected on $\mathrm{Ti} \cdots \mathrm{N}$ coordination, showing a decrease in frequency of only $5 \mathrm{~cm}^{-1}$ in $\mathrm{TiO}_{2}(\mathrm{~B}, \mathrm{R})-$ Phen samples, and remaining the same in both the physical blend and the Phen alone. This is quite expected since the heterocycle ring has the nitrogen donor site, which is able to coordinate with the Ti(IV) atom of the titania, as suggested by the NMR analyses. ${ }^{42,43}$ Thus, there is an effective incorporation of Phen into the titania via Ti-N bonding.

This was further corroborated by XPS analysis. The survey spectrum of the hybrid $\mathrm{TiO}_{2}(\mathrm{~B}, \mathrm{R})$-Phen evidences the presence 
of $\mathrm{Ti}, \mathrm{O}, \mathrm{N}$ and $\mathrm{C}$ in the samples contains not only $\mathrm{Ti}, \mathrm{O}$ and $\mathrm{C}$, but also a small amount of $\mathrm{N}$ (not shown here). From XPS in the Ti2p region of both $\mathrm{TiO}_{2}(\mathrm{~A})$ and the $\mathrm{TiO}_{2}(\mathrm{~A}) /$ Phen physical blend, we found that symmetric Ti( $2 p)$ features, $2 p^{3 / 2}$ and $2 p^{1 / 2}$ appear at 458.16 (458.08) and 463.89 (463.81) eV, respectively - Fig. $\mathrm{S} 3 \mathrm{~A}$. In the $\mathrm{O} 1 \mathrm{~s}$ XPS spectra - Fig. S3B, the characteristic main peak at $529.5 \mathrm{eV}$ is attributed to the oxygen in the metal oxide (Ti-O-Ti bonds), while the $531.2 \mathrm{eV}$ feature is related to the oxygen in a surface hydroxyl (Ti-OH species) and the $\mathrm{H}-\mathrm{O}$ from the absorbed $\mathrm{H}_{2} \mathrm{O}$ on their surface. Additional peaks at ca. 532.9 $\mathrm{eV}$ are usually attributed to chemisorbed species (such as adsorbed $\mathrm{H}_{2} \mathrm{O}$ or $\mathrm{O}_{2}$ or oxygen-containing hydrocarbon contamination) on the surface of the $\mathrm{TiO}_{2}(\mathrm{~A}){ }^{46,47,48} \mathrm{~A}$ red shift has been observed in both Ti2p and $01 s$ peaks of the hybrid $\mathrm{TiO}_{2}(\mathrm{~B}, \mathrm{R})$-Phen. In short, the Ti2p bands appeared at 457.90 and $463.67 \mathrm{eV}$ - Fig. S3A. The energy differences between both $\mathrm{Ti}(2 \mathrm{p})$ peaks is consistent to the $\mathrm{Ti}(\mathrm{IV})$ coordination sites in crystalline titania. These bands do not show additional lower binding energy components associated with the presence of reduced Ti(III) species. Quantitative analyses of these samples in the $\mathrm{C} 1 \mathrm{~s}$ and $\mathrm{N} 2 \mathrm{p}$ regions could not be carried out because of the presence of adventurous carbon and nitrogen in the XPS chamber. XPS in the N1s region clearly shows a signal at ca. $399,31 \mathrm{eV}$, which has been previously attributed to N-Ti-O bond in N-doped titanias - Fig. S4. ${ }^{17,21,49,50}$ Furthermore, there is slight shift in the N1s signal with respect to the phenanthroline alone, which is in agreement with their complexation with transition metals. ${ }^{51}$ This clearly proves that the Ti-N bond is maintained throughout the synthesis of the material.

After having described the successful incorporation of Phen into the titania, we determined the crystalline nature of the titanias. As shown in Fig. $2 \mathrm{C}$ and $3 \mathrm{~J}-\mathrm{L}$, hybrid $\mathrm{TiO}_{2}(\mathrm{~B}, \mathrm{R})-\mathrm{Phen}$ present strong diffraction peaks at $2 \theta=27.6^{\circ}(110), 36.4^{\circ}(101)$, $41.6^{\circ}(111)$, and $54.7^{\circ}$ (221), which can be indexed to the tetragonal structure of rutile (JCPDS 21-1276). The characteristic peaks of the brookite structure (JCPDS 29-1360) at $2 \theta=25.5^{\circ}(120), 25.9^{\circ}(111)$ and $31.0^{\circ}(121)$, are also clearly observed, indicating a biphasic brookite-rutile structure. . $5,3,52,53,11$ The particle size calculated by applying the Scherrer equation to the deconvoluted main peaks of rutile $\left(27.6^{\circ}\right)$ and brookite $\left(31.0^{\circ}\right)$ is in the range of $22-25 \mathrm{~nm}$ for the rutile and 15-19 $\mathrm{nm}$ for the brookite in all crystalline samples see Table 1 . It is well known that the most intense peaks of brookite at $2 \theta=25.5^{\circ}(120)$ and $25.9^{\circ}(111)$ could mask the main peak of anatase phase at $c a .2 \theta=25.5^{\circ}$ (101). Taking into account the peak positions and intensities of the different peaks, the X-ray diffraction patterns of $\mathrm{TiO}_{2}(\mathrm{~B}, \mathrm{R})$-Phen samples were fitted by $50 \%-50 \%$ Lorentzian-Gaussian curves, the peak positions and intensities of the peaks discarding the presence of the anatase phase - see Fig. S5 and ESI for further details.

Furthermore, we also characterized the samples by Raman spectroscopy - Fig. 2F. For comparison purposes, the Raman spectrum of the unmodified titania is also included. It should be noted that the most intense Raman bands of the anatase, rutile, and brookite polymorphs appear in the $143-150 \mathrm{~cm}^{-1}$ range, below the Raman shift range that we are able to measure. Nevertheless, the $\mathrm{TiO}_{2}(\mathrm{~B}, \mathrm{R})$-Phen spectrum clearly shows two of the four Raman active modes of rutile with symmetries $E_{g}$ and $A_{1 g}$ at 426 and $618 \mathrm{~cm}^{-1}$, respectively. ${ }^{5,53}$ The Raman bands at 320 and $503 \mathrm{~cm}^{-1}$ are in good agreement with the B1g modes of brookite. ${ }^{4,11}$ The broad peak at $c a .243 \mathrm{~cm}^{-1}$ has been attributed to the $B_{3 g}$ modes of brookite and multi-phonon

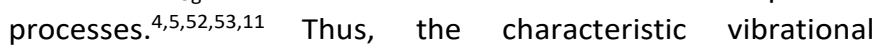
frequencies support the mixing of rutile and brookite phases in the $\mathrm{TiO}_{2}(\mathrm{~B}, \mathrm{R})$-Phen materials.

Finally, TEM analysis of the hybrid $\mathrm{TiO}_{2}(B, R)$-Phen materials also confirms their biphasic crystalline structure - Fig. 3 . The lattice fringes with an interplanar spacing of $c a$. 0.34-0.35 nm are consistent with the planar distance between both the (120) and (110) planes of brookite and rutile, respectively - Fig. 3A-C. The SAED patterns of the TEM images taken at low magnifications - Fig. 3D-F - exhibit a set of bright rings which are characteristic of polycrystalline materials - see Fig. 3G-I. The comparison of the reciprocal of radius of the SAED rings with the standard PDF cards allowed us to identify the specific diffractions of rutile and brookite, and to further compare it with the X-ray synchrotron data, thus confirming the biphasic structure of the hybrid $\mathrm{TiO}_{2}(\mathrm{~B}, \mathrm{R})$-Phen by both techniques - see Fig. 3J-L.

In view of all of the aforementioned, we can conclude that the addition of Phen to the synthesis media modifies the crystallization of the titania yielding a biphasic brookite-rutile structure, in contrast with the expected anatase-brookite $(14 \%$ brookite) obtained when no Phen was used during the synthesis - sample $\mathrm{TiO}_{2}(\mathrm{~A})$, Fig. S6.

The synchrotron X-ray diffraction data was used to study the phase evolution of the crystalline phases with the crystallization time - Table 1 and Fig. $3 \mathrm{H}-\mathrm{I}$. For instance, $\mathrm{TiO}_{2}(\mathrm{~B}, \mathrm{R})-\mathrm{Phen}$ begins to crystallize, after $24 \mathrm{~h}$ at $100{ }^{\circ} \mathrm{C}$, yielding mainly brookite. The percentage of rutile increases with crystallization time, both phases having similar contributions at crystallization times of 36 $\mathrm{h}$ and $48 \mathrm{~h}$. It is worth noting that a sharp decrease in the Phen content has been registered by TG after $48 \mathrm{~h}-$ see Fig. S7 and Table $1,2^{\text {nd }}$ column, which is accompanied to a decrease in the $B E T$ area. This observation suggests an optimum crystallization time of $c a$. $36 \mathrm{~h}$ for $\mathrm{TiO}_{2}(\mathrm{~B}, \mathrm{R})$-Phen materials.

The interparticle mesoporosity is thus significantly affected by both the phase composition and Phen content - see Table 1 and Fig. S8. In detail, $\mathrm{TiO}_{2}(\mathrm{~B}, \mathrm{R})$-Phen materials present specific surface areas between 100 and $350 \mathrm{~m}^{2} \mathrm{~g}^{-1}$, depending on the crystallization time or phase distributions - Table 1. Focusing on samples prepared after $36 \mathrm{~h}$ of crystallization at $100{ }^{\circ} \mathrm{C}$, the specific surface area of the hybrid $\mathrm{TiO}_{2}(\mathrm{~B}, \mathrm{R})$-Phen is only slightly lower ( $c a .160 \mathrm{~m}^{2} \mathrm{~g}^{-1}$ ) than that of unmodified $\mathrm{TiO}_{2}$ synthesized under the same conditions (ca. $200 \mathrm{~m}^{2} \mathrm{~g}^{-1}$ ), sample $\mathrm{TiO}_{2}(\mathrm{~A})$. This difference is in line with the bigger crystallite size of the former. Indeed, the surface area of the hybrid $\mathrm{TiO}_{2}(\mathrm{~B}, \mathrm{R})$-Phen is also higher than that of the commercial P25 $\left(65 \mathrm{~m}^{2} \mathrm{~g}^{-1}\right)$ - Fig. 2D, which could provide an additional advantage to our materials in the photocatalytic degradation of dyes, as later shown.

Another critical aspect is the activation of the photocatalyst with visible light. This could be achieved by reducing the band gap, i.e., changing the position of the conduction ( $\mathrm{CB}$ ) and valence $(\mathrm{VB})$ bands by introducing intermediate energetic 
$24 \mathrm{~h}$
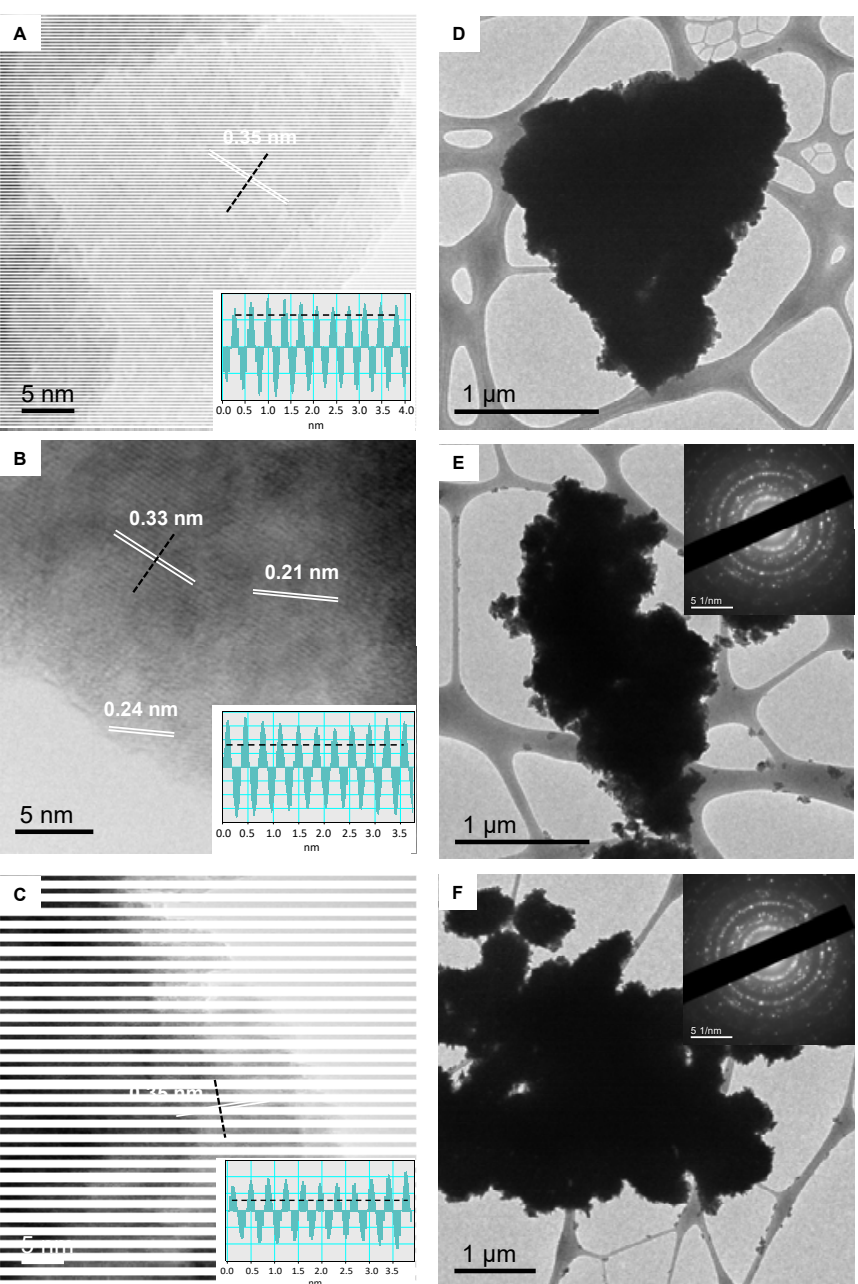
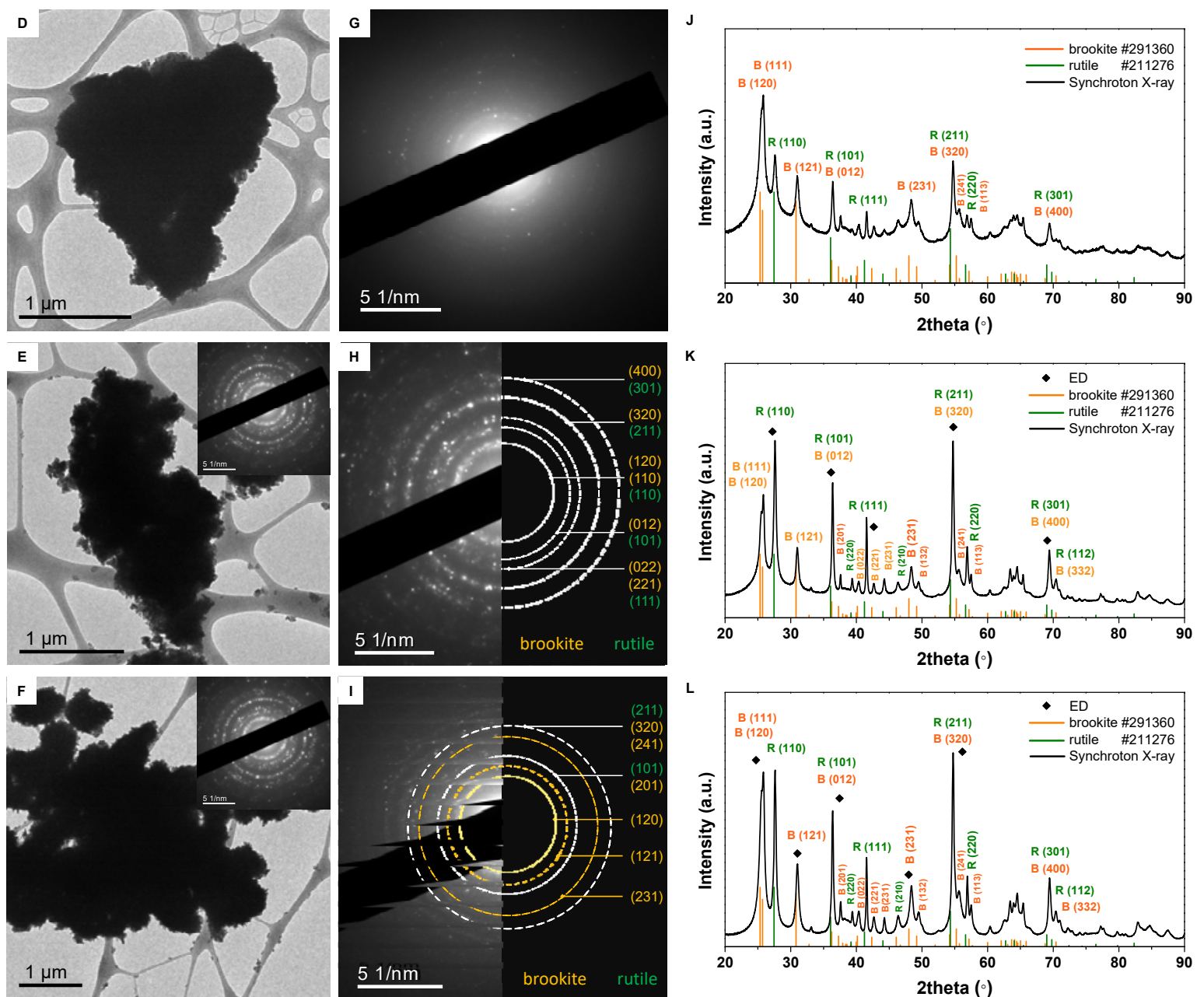

Fig 3. (A-F) TEM micrographs at two different magnifications of the hybrid TiO2(B,R)-Phen at different crystallization times at 100 ㄷ: (up) $24 \mathrm{~h}$, (middle) $36 \mathrm{~h}$, and (bottom) $48 \mathrm{~h}$. (G-I) Selected area electron diffraction (SAED) patterns of the TEM images shown in $D, E$ and $F$, respectively. (J-L) X-ray synchrotron patterns showing the reflexions corresponding to the rutile and the brookite phases, and the 2theta data calculated from the SAED analysis. XRD patterns of the standard PDF cards of rutile and brookite are included in $(\mathrm{J}-\mathrm{L})$ for comparison purposes. Inset in $(\mathrm{A}-\mathrm{C})$ represents the profile of the inverse FFT corresponding to the main lattice spacing. The inset in $(\mathrm{D}, \mathrm{F})$ corresponds to the original ED patterns shown in (H-I) 
states, and by sensitization. Concerning the optical band gap of titania polymorphs, there is a consensus indicating values of $3.0 \mathrm{eV}$ for rutile, 3.2 eV for anatase, and 3.1-3.6 eV for brookite. $^{9,54}$ An important benefit of using Phen in the synthesis of the $\mathrm{TiO}_{2}(\mathrm{~B}, \mathrm{R})$-Phen is that this causes a significant reduction in its band gap down to $2.92 \mathrm{eV}-$ Fig. 4A. As proved by XPS measurements, Ti-N bond is maintained throughout the synthesis of the material. Hence, the band gap reduction is attributed to the presence of intermediate $\mathrm{N}$ energy levels due to these $\mathrm{Ti}-\mathrm{N}$ bonds that, similar to $\mathrm{N}$-doping, typically activates the visible excitation of titanias.

On the other hand, the position of the conduction (CB) and valence (VB) bands of the three titania polymorphs is a longstanding controversy. A comparison between the band edge positions of our materials and few reported values for titanias $^{55-59}$ after their conversion to the Reversible Hydrogen Electrode (RHE) at $\mathrm{pH}=7$ is shown in Fig. $4 \mathrm{C}$. For instance, in anatase-rutile mixtures, the $\mathrm{VB}$ of anatase lies $0.2-0.4 \mathrm{eV}$ alternatively above or below that of rutile. ${ }^{54}$ Recent studies support the hypothesis of a type II-anatase energy band alignment lying the VB of anatase $0.4 \mathrm{eV}$ below that of rutile. $^{54,56}$ The position of the VB of our Phen-free (anatase) $\mathrm{TiO}_{2}(\mathrm{~A})$ is in agreement with our previously reported values for this material (ca. $2.24 \mathrm{eV}$ vs. NHE). ${ }^{29-31}$ We found a shift to higher binding energies (ca. $0.42 \mathrm{eV}$ ) in the VB maximum energy of the hybrid $\mathrm{TiO}_{2}(\mathrm{~B}, \mathrm{R})$-Phen, which agree with both the anatase-to-rutile transition ${ }^{54,56,59}$ and also to the energy level N2p due to the Phen incorporation - Fig. 4B,C. In any case, besides the change in the crystalline structure, the blue shift in the onset of absorption up to $425 \mathrm{~nm}$ suggests that the Phen incorporation allows the synthesis of hybrid-titania with enhanced visible light-driven photocatalytic activity.

Regarding the role of the Phen as crystal modifier to yield rutile/brookite systems, we suggest that the geometry of the complex formed between the Phen and the titanium alkoxyde used as titania precursor fundamentally changes the crystallization pathway yielding a mixture of the rutile and brookite phases, which are structurally more similar to the organotitania precursor - Scheme 1 . The fundamental structure unit in the three main titania polymorphs - i.e., anatase, brookite, and rutile - are all $\left[\mathrm{TiO}_{6}\right]$ octahedron, but their modes of arrangement and link are different. ${ }^{60} \mathrm{It}$ is well known that the crystal structure and phase composition of titanias prepared by hydrothermal method depend on the hydrothermal conditions, such as $\mathrm{pH}$, temperature, and time. ${ }^{6}$ Furthermore, as described in the Introduction section, the addition of ligands that coordinate with the Ti(IV) atom in titanium alkoxydes play a key role in the crystallization of a specific polymorph. On this regard, the phase that is favored depends upon the coordination of $\mathrm{Ti}(\mathrm{IV})$ complex ions and its structural similarity to the polymorph. ${ }^{6,19,24,26-28}$ Hence, on the basis that crystalline phase of hybrid $\mathrm{TiO}_{2}(\mathrm{~B}, \mathrm{R})$-Phen differs from the one of unmodified titania, we hypothesize that the chemical structure of the TBOT-
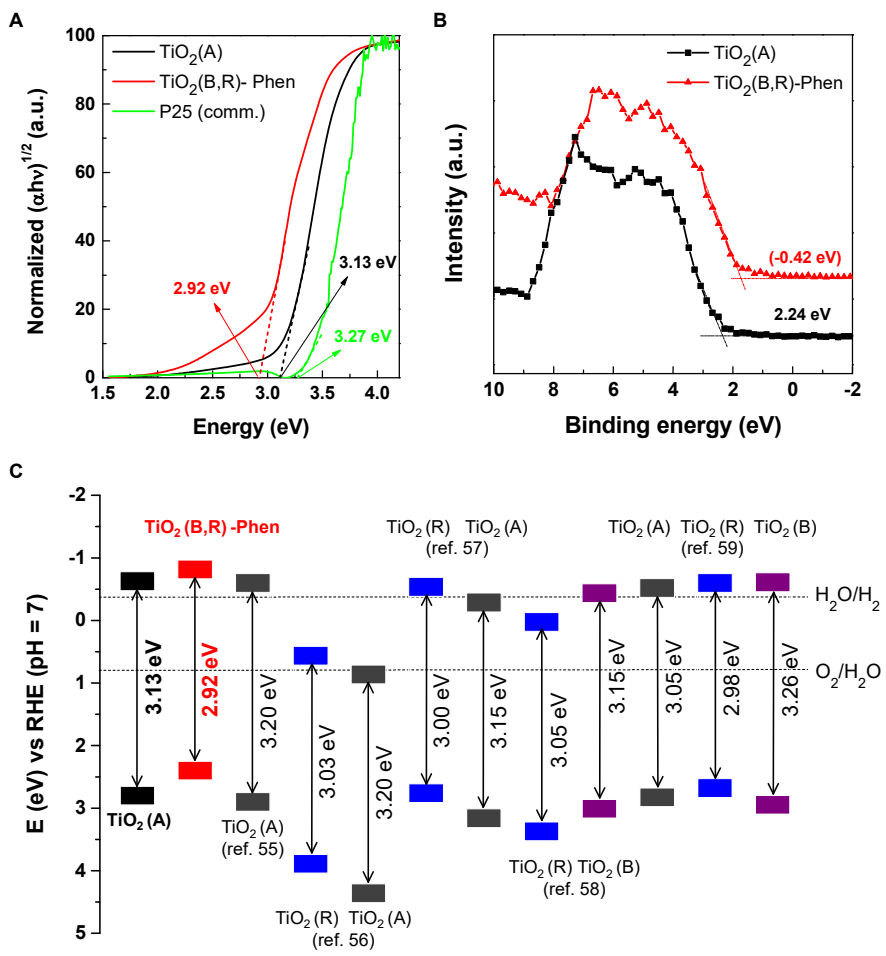

Fig 4 (A) Tauc plot of the transformed Kubelka-Munk function versus the energy of the light absorbed, and (B) XPS spectra in the valence band region of the hybrid $\mathrm{TiO}_{2}(\mathrm{~B}, \mathrm{R})$-Phen (crystallization time $36 \mathrm{~h}$ ), as compared with the Phen-free titania prepared using the same synthetic conditions $-\mathrm{TiO}_{2}(\mathrm{~A})$, black squares/line- and the commercial P25 (green line). (C) DOS scheme of our materials as compared to the reported values for titanias ${ }^{55-59}$ vs. $\mathrm{RHE}(\mathrm{pH}=7)$.

Phen complex used as a precursor - Scheme 1,i - favors the formation of the brookite and rutile structures - Scheme 1, iii -, the Phen content determining the rutile-to-brookite ratio Table 1.

\section{Photocatalytic activity}

The photocatalytic performance of our materials was evaluated for the degradation of cationic dyes that are typically used as model compounds - i.e., rhodamine 6G (Rh6G), rhodamine B $(\mathrm{RhB})$ and methylene blue $(\mathrm{MB})$ - in aqueous solutions. $A$ photochemical reactor system equipped with a $400 \mathrm{~W}$ mediumpressure Hg lamp was used (Scheme S1). The UV light was filtered by filling the double-walled quartz immersion with a $\mathrm{NaNO}_{2}$ solution that allows the passing of only visible light (liquid cut-off filter $>400 \mathrm{~nm})^{61}$ - see Methods, Table S1, Scheme S1 and ESI for details.

In the first set of experiments, we considered the effect of the $\mathrm{TiO}_{2}(\mathrm{~B}, \mathrm{R})$-Phen content in the degradation reaction of Rh6G - Fig. 5 and S9. As expected, photocatalytic activity increases with the $\mathrm{TiO}_{2}(\mathrm{~B}, \mathrm{R})$-Phen content up to a certain value, beyond which the activity holds constant. Hence, a photocatalysts concentration of $0.40 \mathrm{~g} / \mathrm{L}$ in $100 \mathrm{ml}$ of $1 \times 10^{-5} \mathrm{M}$ aqueous dye solutions has been chosen for the rest of experiments, which were carried out under identical irradiation conditions, using the Scheme S1. This allows us the qualitative comparison 
Table 2 Constant values of the photocatalytic activity under VIS irradiation, regression coefficients and conversions at different times of the hybrid $\mathrm{TiO}_{2}(\mathrm{~B}, \mathrm{R})$ Phen (crystallization time $36 \mathrm{~h}$ ) compared with the control experiments, in the degradation reaction of aqueous R6G solutions. Experiments were carried out under identical irradiation conditions, using $40 \mathrm{mg}$ of photocatalyst and $100 \mathrm{ml}$ of $1 \times 10^{-5} \mathrm{M}$ aqueous Rh6G solutions.

\begin{tabular}{|c|c|c|c|c|c|c|c|}
\hline \multirow{2}{*}{ Samples } & \multirow{2}{*}{$\begin{array}{l}\mathrm{E}_{\mathrm{g}}{ }^{a} \\
(\mathrm{eV})\end{array}$} & \multirow{2}{*}{$\begin{array}{l}\mathrm{k}^{\prime *} 10^{3, b} \\
\left(\mathrm{~min}^{-1}\right)\end{array}$} & \multirow{2}{*}{$\mathrm{R}^{2, b}$} & \multicolumn{3}{|c|}{ Conversion $^{c}(\%)$} & \multirow{2}{*}{$\begin{array}{l}\mathrm{k}^{\prime} / \mathrm{k}^{\prime} \mathrm{P} \\
{ }_{25}{ }^{d}\end{array}$} \\
\hline & & & & $20^{\prime}$ & $1 \mathrm{~h}$ & $2 \mathrm{~h}$ & \\
\hline P25 & 3.3 & $\begin{array}{c}1.8 \pm 0.3 \\
(1.6)\end{array}$ & $\begin{array}{c}0.987 \\
2\end{array}$ & 6 & 10 & 17 & --- \\
\hline $\begin{array}{c}\mathrm{TiO}_{2}(\mathrm{~B}, \mathrm{R}) \\
\text {-Phen }\end{array}$ & 2.9 & $\begin{array}{c}17.6 \pm 0.4 \\
(17.9)\end{array}$ & $\begin{array}{c}0.996 \\
6\end{array}$ & 36 & 68 & 86 & $\begin{array}{r}10.0 \\
\pm 1.9\end{array}$ \\
\hline $\mathrm{TiO}_{2}(\mathrm{~A})$ & 3.1 & $\begin{array}{c}1.9 \pm 0.2 \\
(1.7)\end{array}$ & $\begin{array}{c}0.978 \\
2\end{array}$ & 5 & 11 & 18 & $\begin{array}{c}1.1 \pm \\
0.3\end{array}$ \\
\hline Blend $^{e}$ & --- & 1.7 & $\begin{array}{c}0.991 \\
5 \\
\end{array}$ & 5 & 10 & 19 & 1 \\
\hline
\end{tabular}

${ }^{a}$ Band gap energies calculated from the intercept of the tangent to the $\left(\mathrm{F}\left(\mathrm{R}^{\prime}\right) h v\right)^{1 / 2}$ versus $(h v)$ plot. ${ }^{b}$ Pseudo-first order rate constant $\left(\mathrm{K}^{\prime}\right)$ and regression coefficient $\left(R^{2}\right)$ of the photodegradation of $100 \mathrm{ml}$ of aqueous solutions of Rh6G $\left(1 \times 10^{-5} \mathrm{M}\right)$, obtained as the average of a three runs. Values in brackets indicate the $k^{\prime}$ value used for the determination of the degree of conversion shown in Table 2 (see also Fig. S9E). ${ }^{c}$ Conversion achieved by the samples after $20 \mathrm{~min}, 1 \mathrm{~h}$ and $2 \mathrm{~h}$ of reaction. ${ }^{d}$ Ratio between the average $k^{\prime}$ values of each of the experiments carried out using $40 \mathrm{mg}$ of the different photocatalyst as compared with the average $k^{\prime}$ value determined when using $40 \mathrm{mg}$ of the commercial P25 as reference. ${ }^{e}$ Physical blend of $\mathrm{TiO}_{2}(\mathrm{~A})$ with 12 wt\% Phen.
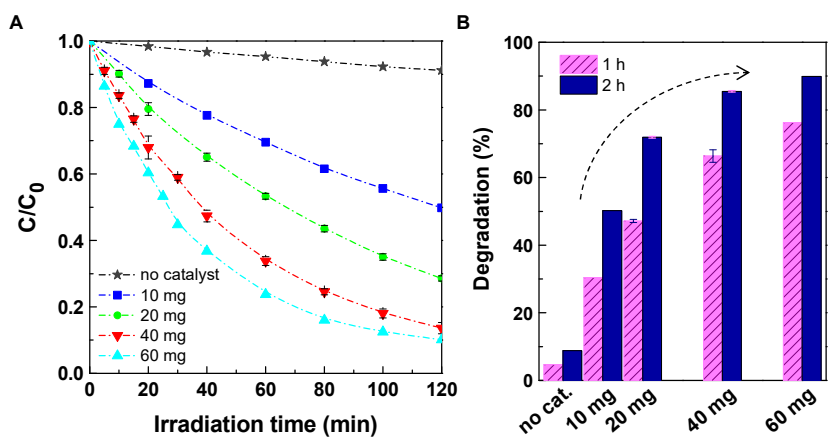

Fig. 5 Effect of the hybrid $\mathrm{TiO}_{2}(\mathrm{~B}, \mathrm{R})$-Phen loading on the photocatalytic degradation reaction of Rh6G: (A) photodegradation profiles, and (B) degree of conversion achieved after $1 \mathrm{~h}$ and $2 \mathrm{~h}$ of reaction as a function of the $\mathrm{TiO}_{2}(\mathrm{~B}, \mathrm{R})$-Phen loading. Experiments were carried out under identical irradiation conditions, using $100 \mathrm{ml}$ of $1 \times 10^{-5} \mathrm{M}$ aqueous Rh6G solutions.

between the photocatalytic activity of the different catalysts and dyes tested. ${ }^{62,63}$

Next, the efficiency of the $\mathrm{TiO}_{2}(\mathrm{~B}, \mathrm{R})$-Phen photocatalyst was evaluated in comparison with commercial P25, the synthesized $\mathrm{TiO}_{2}(\mathrm{~A})$, and its mixture with Phen (physical blend) - Figs. 6 andS10, and Table 2. As previously reported for $\mathrm{N}$-doped titanias, ${ }^{17}$ both unmodified $\mathrm{TiO}_{2}(\mathrm{~A})$ and $\mathrm{TiO}_{2}(\mathrm{~B}, \mathrm{R})$-Phen reveal similar photoactivity under UV light. Under visible light (sodium nitrite filter), stark differences have, however, been noted. The hybrid $\mathrm{TiO}_{2}(\mathrm{~B}, \mathrm{R})$-Phen exhibits a 10 -fold enhanced activity in comparison with the reference materials, giving decomposition
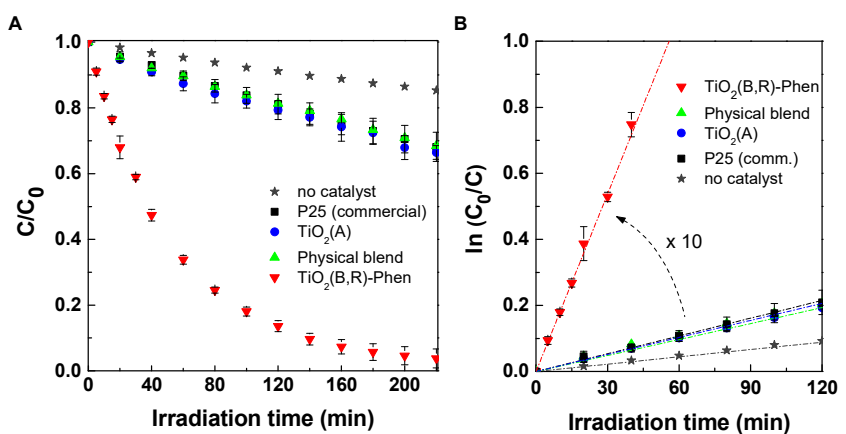

Fig. 6 Rh6G photodegradation reaction using the hybrid $\mathrm{TiO}_{2}(\mathrm{~B}, \mathrm{R})$-Phen as photocatalyst, as compared with the Phen-free titania, $\mathrm{TiO}_{2}(\mathrm{~A})$, the commercial $\mathrm{P} 25$, and physical blend of $\mathrm{TiO}_{2}(\mathrm{~A})$ with $12 \mathrm{wt} \%$ Phen (Physical blend): (A) changes in the Rh6G concentration, and (B) plots of $\ln \left(C_{0} / C\right)$ as a function of the irradiation time (symbols) with their corresponding linear fits (dashed lines). Experiments were carried out under identical irradiation conditions, using $40 \mathrm{mg}$ of photocatalysts and $100 \mathrm{ml}$ of $1 \times 10^{-5} \mathrm{M}$ aqueous Rh6G solutions.

rates of ca. $86 \pm 2 \%$ after $2 \mathrm{~h}$ of irradiation - see Table 2 and Fig. S10E. It should be noted that the photocatalytic activity of unmodified titania remains the same before - black squares in Fig. 6 - and after their physically mixing with $12 \mathrm{wt} \%$ Phen purple triangles in Fig. 6, which further evidences the benefits of the hybrid nature of the $\mathrm{TiO}_{2}(\mathrm{~B}, \mathrm{R})$-Phen. Finally, Rh6G degradation experiments were also carried out using blue LEDs (435-445 $\mathrm{nm}$ spectral range). In this case, even with the lower radiance that LEDs offer regarding mercury arc lamps, the hybrid material is still able to enhance the photocatalytic activity. In fact, the pseudo-first order rate constant of the hybrid $\mathrm{TiO}_{2}(\mathrm{~B}, \mathrm{R})$-Phen is twice the one corresponding to the reference $\mathrm{TiO}_{2}(\mathrm{~A})$.

Taking into account the outstanding photocatalytic activity of the hybrid $\mathrm{TiO}_{2}(\mathrm{~B}, \mathrm{R})$-Phen, we moved forward the photodegradation of other cationic dyes - Fig. 7, S11 and S12, maintaining a photocatalysts concentration of $0.40 \mathrm{~g} / \mathrm{L}$, and using $100 \mathrm{ml}$ of $1 \times 10^{-5} \mathrm{M}$ aqueous dye solutions. In the same line, $\mathrm{TiO}_{2}(\mathrm{~B}, \mathrm{R})$-Phen presents a 6-fold and 3-fold, respectively, enhanced photodegradation activity of $\mathrm{MB}$ and $\mathrm{RhB}$ compared
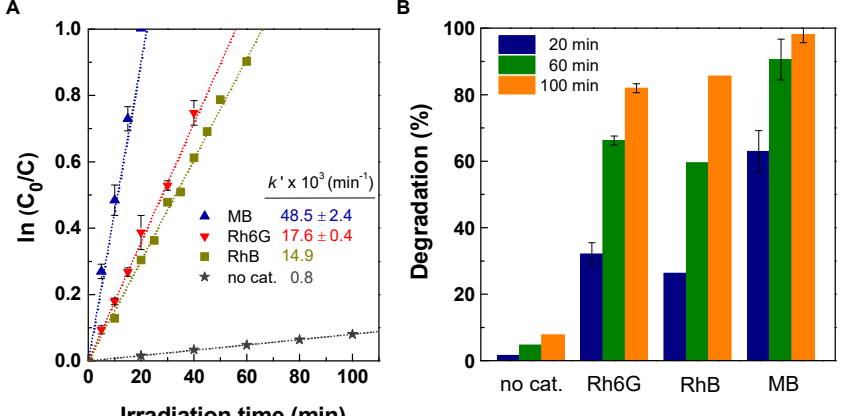

Fig. 7 Photocatalytic activity of hybrid $\mathrm{TiO}_{2}(\mathrm{~B}, \mathrm{R})$-Phen in the degradation reaction of Rh6G, RhB and MB: (A) plots of $\ln \left(C_{0} / C\right)$ as a function of the irradiation time (symbols) with their corresponding linear fits (dashed lines), and (B) degradation at different irradiation times. Inset in (A) shows the apparent constant rate $\left(k^{\prime} \times 10^{-3}, \mathrm{~min}^{-1}\right)$ for each degradation reaction. Experiments were carried out, under identical irradiation conditions, using a $400 \mathrm{~W}$ medium-pressure mercury lamp (sodium nitrite liquid cut-off filter) as light source, $40 \mathrm{mg}$ of photocatalysts and $100 \mathrm{ml}$ of $1 \times 10^{-5} \mathrm{M}$ aqueous dye solutions. 
A

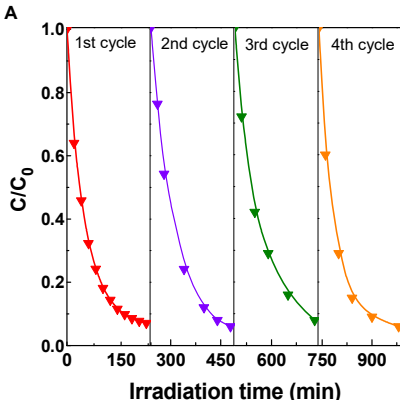

B

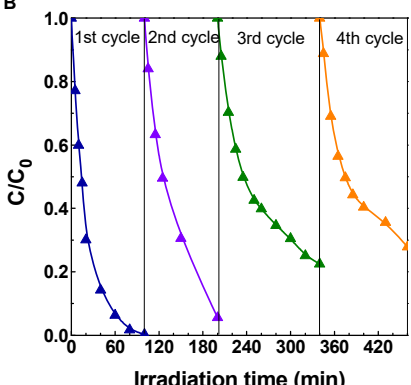

Fig. 8 Recycling tests of: (A) Rh6G and (B) MB degradation over identical $\mathrm{TiO}_{2}(\mathrm{~B}, \mathrm{R})$-Phen samples. Experiments were carried out under identical irradiation conditions, using a 400 W medium-pressure mercury lamp (sodium nitrite liquid cut-off filter) as light source, $0.4 \mathrm{~g} / \mathrm{L}$ of catalyst and a dye concentration (both Rh6G and $\mathrm{MB}$ ) of $1 \times 10^{-5} \mathrm{M}$.

to those of the unmodified titanias - Fig. 7B and S11 - achieving decomposition rates $>80 \%$ after 100 min of irradiation - Fig. 7B.

Next, recycling tests were carried out to assess the stability and reusability of the hybrid $\mathrm{TiO}_{2}(\mathrm{~B}, \mathrm{R})$-Phen as photocatalyst (see ESI for details). As shown in Fig. 8, the hybrid material retains, after four photodegradation cycles, $>90 \%$ (Rh6G, Fig. $8 \mathrm{~A})$ and $c a .70 \%$ (MB, Fig. 8B) of its corresponding efficiency. These results clearly point out the excellent stability and reusability of the hybrid $\mathrm{TiO}_{2}(\mathrm{~B}, \mathrm{R})$-Phen under the tested conditions.

After the photocatalytic degradations, recovered photocatalysts were characterized by FTIR and TG measurements, and the dye solutions were analyzed by HPLCmass spectrometry. Fig. S13 shows FTIR and TG data of $\mathrm{TiO}_{2}(\mathrm{~B}, \mathrm{R})$-Phen before and after the $\mathrm{MB}$ degradation process shown in Fig. 7. Both FTIR spectra and TG curves of the recovered catalyst remained almost unchanged, which further confirms the stability of the synthesized $\mathrm{TiO}_{2}(\mathrm{~B}, \mathrm{R})$-Phen.

Next, the HPLC-mass spectrometry analysis of the dye solutions before and after is discussed - see ESI and Fig.s S1417. The total ion chromatogram (TIC, positive mode) of the initial solutions of Rh6G (and RhB) shows a sharp intense peak at ca. $5.0 \mathrm{~min}$ ( $4.9 \mathrm{~min}$ for $\mathrm{RhB}$ ), as well as two very low intense peaks at retentions times of $4.9 \mathrm{~min}$ (for Rh6G) and $4.6 \mathrm{~min}$ (for both Rh6G and RhB) - Fig. S14. The molecular mass $(\mathrm{m} / \mathrm{z})$ of both Rh6G and RhB cations (after chloride deionization) is 443, which is observed at $5.0 \mathrm{~min}$ and $4.9 \mathrm{~min}$, respectively. The mass spectra of the low intense peaks indicates $\mathrm{m} / \mathrm{z}$ values of 429 and 415 , corresponding to the deethylated and demethylated cations, respectively, in a very low concentration- Fig.s S15 and S16. Similarly, the chromatogram of the control MB shows an intense peak at retention times of $3.8 \mathrm{~min}$, which corresponds to the molecular mass of the MB cation $(\mathrm{m} / \mathrm{z}=284)$, and a small peak at $3.7 \mathrm{~min}$ due to the demethylated $\mathrm{MB}(\mathrm{m} / \mathrm{z}=270)$ - Fig. $\mathrm{S} 14$ and S17. After the degradation processes, the original peaks disappeared in all cases, which suggests the degradation of the cationic dyes under visible light -Fig. S14. ${ }^{64}$ Indeed, high molar mass fragments typically associated to intermediate Rh6G or RhB degradation products were not detected by MS analysis Fig. S15 and S16. ${ }^{65-68}$ In the case of MB, we identified the thionin intermediate $(\mathrm{m} / \mathrm{z}=228)$ after $100 \mathrm{~min}$ of reaction, suggesting that the MB degradation occurs via the auxochrome group

degradation, i.e. via demethylation cleavage during the photo catalytic degradation ${ }^{69,70}$ - Fig. S17.

In the case of the photodegradation of the cationic dyes using $\mathrm{TiO}_{2}(\mathrm{~A})$ and $\mathrm{P} 25$ reference catalysts, the blockage of radiation below $400 \mathrm{~nm}$ prevents the hole way. ${ }^{61}$ By contrast, the improved photoactivity under visible light of the hybrid $\mathrm{TiO}_{2}(\mathrm{~B}, \mathrm{R})-$ Phen could be ascribed to the synergistic combination of its reduced band gap, due to the Ti- $\mathrm{N}$ bonding, and the presence of the biphasic brookite-rutile that reduces carrier recombination, promoting the self-degradation of dyes adsorbed on the surface. The former is in line with Asahi et al. ${ }^{17}$ who first described the visible-light induced photoactivity of $\mathrm{N}$ doped titanias. This mechanism is promoted by blue-absorbing states induced by the introduction of $\mathrm{N} 2 \mathrm{p}$ levels that leads to i) $\mathrm{CB}$ levels higher than the $\mathrm{H}_{2} / \mathrm{H}_{2} \mathrm{O}$ level with good photoreduction activity - Fig. 4C, and ii) low carrier recombination upon excitation. The latter is also promoted by the high photoreactivity of brookite phases and the carrier stabilization at the interphase lattice with rutile, leading to more robust titania-based photocatalyst. These features were confirmed by applying current-voltage (J-V) and electrochemical impedance spectroscopy (EIS) assays to $\mathrm{TiO}_{2}(\mathrm{~B}, \mathrm{R})$-Phen and $\mathrm{TiO}_{2}$ electrodes under 1 sun and dark conditions - see experimental section for details. In short, J-V assays showed that the photogenerated current of $\mathrm{TiO}_{2}(\mathrm{~A})$ electrodes is 2.5 times higher than those with $\mathrm{TiO}_{2}(\mathrm{~B}, \mathrm{R})-\mathrm{Phen}$, indicating a more prominent charge trapping in the latter - Fig. S18. This was confirmed by EIS measurements under illumination - Fig. S19. At open circuit conditions, the charge transport resistances were $8.74 \mathrm{k} \Omega$ and $22.3 \mathrm{k} \Omega$ for $\mathrm{TiO}_{2}(\mathrm{~A})$ and $\mathrm{TiO}_{2}(\mathrm{~B}, \mathrm{R})-$ Phen electrodes, respectively. This difference hold constant over a voltage range from 0 to $0.3 \mathrm{~V}-$ Fig. S18. In addition, EIS assays under dark conditions provide valuable information about the resistance towards recombination upon increasing the applied bias - Fig. S2O. Here, $\mathrm{TiO}_{2}(\mathrm{~B}, \mathrm{R})-\mathrm{Phen}$ electrodes present almost 2-fold higher recombination resistance than $\mathrm{TiO}_{2}(\mathrm{~A})$ electrodes - e.g., 34.2 vs. $16.4 \mathrm{k} \Omega$ at open circuit conditions. In other words, the $\mathrm{TiO}_{2}(\mathrm{~B}, \mathrm{R})$-Phen feature reduced carrier recombination rates due to the presence of $\mathrm{N} 2 \mathrm{p}$ states or brookite-rutile interphases.

To gain a deeper insight about the photocatalytic mechanisms involved in the degradation of the dyes, the influence of triethanolamine as a hole scavenger in both the Rh6G and MB degradation was investigated (see ESI for details). Hole scavengers could inhibit the photocatalytic process by reacting with hydroxyl radicals and thus, they may compete with the dye for their adsorption at the surface sites where reactive species are produced. However, they can also boost the photocatalytic efficiency. ${ }^{63,71-73}$ Indeed, hole scavengers have been previously employed to enhance the photocatalytic reduction reaction under UV light in doped titanias. ${ }^{73}$ In our case, the photodegradation rate is increased after the addition of triethanolamine to both Rh6G and $\mathrm{MB}$ dye solutions, suggesting that $i)$ the hole scavenger contributes to the charge separation, ${ }^{73,71}$ and ii) the dominant mechanism is the dye way, i.e., the self-degradation of the cationic dyes. ${ }^{74}$ 


\section{Experimental}

Materials. Chemicals. Tetrabutyl orthotitanate (TBOT, 97\%), 1,10phenanthroline (Phen, >99\%), absolute ethanol (<99.8\%), commercial titania Aeroxide ${ }^{\circledast}$ P25 (P25, $\left.\geq 99.5 \%\right)$, and the dyes rhodamine 6G (Rh6G, 99\%), and rhodamine B (RhB, >99\%) were purchased from Sigma-Aldrich and used without further purification. Methylene blue (MB, high purity) was supplied by Alfa-Aesar.

Synthetic procedures. Synthesis of the hybrid titaniaphenanthroline, $\mathrm{TiO}_{2}(\mathrm{~B}, \mathrm{R})-\mathrm{Ph}$. The main paragraph text follows directly on here. The synthesis of hybrid $\mathrm{TiO}_{2}(\mathrm{~B}, \mathrm{R})$-Phen samples was carried out according to our previously reported procedure. ${ }^{29,30}$ In a typical synthesis, the Phen was first dissolved in $35 \mathrm{ml}$ of absolute ethanol under magnetic stirring. Then, $5 \mathrm{~g}$ of TBOT were added to the solution and the mixture was magnetically stirred for 2 hours at room temperature. Finally, $125 \mathrm{~g}$ of water were added drop-wise causing the precipitation of the solid. The mixture was then kept at room temperature under vigorous magnetic stirring for $12 \mathrm{~h}$, followed by treatment at $100{ }^{\circ} \mathrm{C}$, for different times $(0-48 \mathrm{~h})$, under static conditions, in an air oven. The obtained solid product was washed with water, acetone, and ethanol successively, filtered and dried in an oven at $100{ }^{\circ} \mathrm{C}$ for 8 hours. The molar ratio of the synthesis gel was $1 \mathrm{TiO}_{2}: 0.1$ Phen: $467 \mathrm{H}_{2} \mathrm{O}: 41 \mathrm{EtOH}$.

Synthesis of titania nanoparticles, $\mathrm{TiO}_{2}(\mathrm{~A})$. Phen-free titanias were synthesized following the same procedure described above, avoiding the Phen addition.

Preparation of physical blends of $\mathrm{TiO}_{2}(\mathrm{~A})$ with Phen (Physical blend). Physical blends of $\mathrm{TiO}_{2}(\mathrm{~A})$ with 12 wt\% Phen were prepared by mixing both powders using an agate mortar for about $10 \mathrm{~min}$.

Methods. The incorporation of Phen into the titania was evaluated by XPS and FTIR spectroscopy techniques, and the content of the organic compound in the final materials was analyzed by thermogravimetric measurements (TG). The morphology of the materials was investigated by transmission electron microscopy (TEM). The band gap of both the organotitanias and the unmodified titania was estimated by DRUV measurements. XPS spectra of these materials were obtained in the -10 to $2 \mathrm{eV}$ region to calculate the position of the maximum of their valence bands. Both techniques, i.e., DRUV and XPS in the valence band region, were combined to obtain the density of states (DOS) scheme. Band edge positions were converted to the Reversible Hydrogen Electrode (RHE) at $\mathrm{pH}=7$ by using $E_{\mathrm{RHE}} \approx E+0.059 \times \mathrm{pH}$, where $E$ is the potential corresponding to the maximum valence band, as determined by XPS. ${ }^{75}$ Synchrotron Xray diffraction experiments were performed at the ALBA synchrotron located in the Barcelona area, Spain (beamline BL04-MSPD). Porous texture was characterized by $\mathrm{N}_{2}$ physisorption experiments at $77 \mathrm{~K}$ and the results were analyzed using the software package AUTOSORB1 (Quantachrome Corporation).

Photocatalytic activity. The photocatalytic activity of TiO2(B,R)-Phen materials was evaluated in the degradation reaction of different dyes (Rhodamine 6G, Methylene blue and Rhodamine B) in aqueous solution $\left(1 \times 10^{-5} \mathrm{M}\right)$ using a $400 \mathrm{~W} \mathrm{Hg}$ medium-pressure lamp as light source. A 2 M of freshly prepared NaNO2 solution (UV cut-off filter >
$400 \mathrm{~nm}$ ) was introduced in the double-walled quartz immersion well, instead of distilled water, for each of the experiments conducted under visible irradiation. In a typical experiment, the photocatalyst $(0.4 \mathrm{~g} / \mathrm{L})$ was added to $100 \mathrm{ml}$ of a $1 \times 10^{-5} \mathrm{M}$ dye solution. Before irradiation, samples were magnetically stirred for $60 \mathrm{~min}$ in dark to achieve high dispersion and adsorption-desorption equilibrium of the dye on the photocatalyst surface. In all cases, the initial concentration $\left(C_{0}\right)$ has been taken as the concentration after the adsorption-desorption equilibrium was reached. Afterwards, the lamp was turned on and the reaction mixture was irradiated with visible light. The light output, which was estimated using ferrioxalate actinometry under operating conditions, ${ }^{76-78}$ was $2.4 \times 10^{16}$ photons/s. During the photocatalytic reaction, a known volume of sample was withdrawn every $5-20 \mathrm{~min}$ (depending of the system), and the concentration of the Rh6G, RhB or MB species was estimated based on the maximum absorbance observed at ca. $525 \mathrm{~nm}, 550 \mathrm{~nm}$ and $660 \mathrm{~nm}$, respectively, using a UV-vis spectrometer (V650, Jasco Analytica Spain). Some experiments were also carried out using a blue light-emitting diode (LED, 435-445 nm) ring as light source. After the photocatalytic degradations, the photocatalysts were recovered by centrifugation, washed with distilled water and ethanol, and then characterized by FTIR, TG and TEM-SAED. HPLC-mass spectrometry was used for the analysis of the dye solutions before and after the photocatalytic degradations. The detailed information can be found in the ESI.

Photophysics assay. Time resolved spectroscopy was carried out to Rh6G $\left(1 \times 10^{-5} \mathrm{M}, 100 \mathrm{ml}\right)$ in a suspension of $\mathrm{TiO}_{2}(\mathrm{~A})$ or $\mathrm{TiO}_{2}(\mathrm{~B}, \mathrm{R})$ Phen nanoparticles $(0.4 \mathrm{~g} / \mathrm{L})$ excited with a pulsed laser $(442.5 \mathrm{~nm})$.

Preparation pastes and electrodes. Pastes for electrodes were prepared by suspending $\mathrm{TiO}_{2}(\mathrm{~A})$ and $\mathrm{TiO}_{2}(\mathrm{~B}, \mathrm{R})$-Phen nanoparticle in ethanol followed by the addition of $\mathrm{HCl} 1 \mathrm{M}$. Electrodes were deposited by doctor blading technique onto cleaned FTO (See ESI for specific details) and sintered at $200^{\circ} \mathrm{C}$ for $30 \mathrm{~min}$.

Device fabrication. Electrodes were assembled together with platinum counterelectrodes using a polymer spacer. I-//3- electrolyte was injected through pre-drilled holes in the pt-CE.

Characterization of devices. Electrical characterization of devices with $\mathrm{TiO}_{2}(\mathrm{~A})$ and $\mathrm{TiO}_{2}(\mathrm{~B}, \mathrm{R})$-Phen electrodes was performed using a solar simulator previously calibrated with a Si reference cell. J-V curves were obtained applying a linear sweep voltammetry from -0.5 $\mathrm{V}$ to $0.05 \mathrm{~V}$ at dark and 1 sun conditions. Electrochemical Impedance Spectroscopy assays was performed over a voltage range from 0 to $0.3 \mathrm{~V}\left(\mathrm{~J}_{\mathrm{sc}}\right.$ to $\mathrm{V}_{\mathrm{oc}}$ conditions). Results were fitted to an equivalent circuit to extract the transport resistance within each electrode and lifetimes were extracted from the frequency at which maximum phase shift was obtained.

\section{Conclusions}

In summary, we have demonstrated a strategy for the sol-gel synthesis of highly photoactive biphasic brookite-rutile organotitanias. This has been achieved by the incorporation of Phen in a typical synthesis with titanium alkoxides, using water/ethanol and mild temperatures. The role of this 
heterocyclic compound is twofold. On one hand, Phen acts as crystal modifier, driving the crystallization of the titania to yield a biphasic brookite-rutile mixture, due to the geometry of the complex formed through its coordination with the titanium alkoxide precursor, $\mathrm{Ti}(\mathrm{OR})_{4}$. This guarantees a reduced carried recombination rate. On the other hand, Phen is a source of intermediate $\mathrm{N} 2 \mathrm{p}$ states due to the Ti-N bonds, which allows the enhancement of photo-induced electron transfer in the visible range.

Our contribution represents a novel and simple alternative to nitrogen-doped titanias. Instead of introducing the $\mathrm{N}$ atoms in the titania structure either by substitution or interstitial inclusion (doping); our solution is based on the formation of Ti$\mathrm{N}$ bonds by simple coordination of $\mathrm{N}$-containing ligands to the titanium atoms of titania. This is done solely by adding a nitrogen-containing ligand, in this case Phen, to the synthesis solution containing the titanium alkoxide. In this work, we show how the Ti-N bond is maintained throughout the synthesis of the material, and yields the intermediate $N 2 p$ states responsible of the excellent photocatalytic properties under visible light.

Owing to the above feature, $\mathrm{TiO}_{2}(\mathrm{~B}, \mathrm{R})$-Phen photo-catalyst photocatalyst exhibits a significant enhanced visible light photodegradation of cationic pollutants in aqueous solutions compared to the reference titania catalysts $\left(\mathrm{TiO}_{2}\right.$ anatase, $\mathrm{P} 25$, and physical blend of $\mathrm{TiO}_{2}$-Phen). In detail, the hybrid $\mathrm{TiO}_{2}(\mathrm{~B}, \mathrm{R})$ Phen shows a 10 -fold enhanced visible photoactivity keeping their efficiency after four photodegradation cycles. The photocatalyst mechanism is related to the self-degradation of the dyes, which is enhanced by the reduced carrier recombination due to both the binary brookite-rutile structure and the Ti- $\mathrm{N}$ bonds, and the blue absorption features related to the intermediate $\mathrm{N} 2 \mathrm{p}$ states. As such, this work presents a convenient sol-gel synthesis strategy to simultaneously obtain biphasic brookite-rutile organotitanias bearing Ti-N bonds, leading to superior photocatalytic activity in the degradation reaction of aqueous solutions of basic dyes under visible light.

\section{Conflicts of interest}

There are no conflicts to declare.

\section{Acknowledgements}

This work was supported by the Spanish MICINN and AEI/FEDER (projects CTQ2015-74494-JIN and RTI2018-099504-B-C21/AC22). E.S. and N.L. also thanks the University of Alicante through the "Programa de Retención de Talento" (ref. UATALENTO16-03 and 17-05, respectively). E.S. thanks the synchrotron ALBA for beamtime availability (ID 2018022752) and F. Fauth for helpful suggestions with the flow reactor design and assistance during the powder diffraction experiments. We also thank J.J. Carpena Montesinos, from the UA, for assistance with the flow reactor design and construction, and Dr. H. DeColatti from CONICET (Argentine) for his help during the powder diffraction experiments. Dr. Pablo Candela, from the Research Technical Services of the UA, is also acknowledged for this support with the HPLC-mass spectrometry analyses. I.G.P and R.D.C. acknowledge the program "Ayudas para la atracción de talento investigador - Modalidad 1 of the Consejería de Educación, Juventud y Deporte - Comunidad de Madrid with reference number 2016-T1/IND-1463". R. D. C. also acknowledges the Spanish MINECO for the Ramon y Cajal program (RYC-201620891), and HYNANOSC (RTI2018-099504-A-C22). R.D.C. also acknowledges the FOTOART-CM project funded by Madrid region under program P2018/NMT-4367.

\section{Notes and references}

1

C. Belver, J. Bedia, A. Gómez-Avilés, M. Peñas-Garzón and J. J. Rodriguez, in Nanoscale Materials in Water Purification, Elsevier, 2019, pp. 581-651. M. Pelaez, N. T. Nolan, S. C. Pillai, M. K. Seery, P. Falaras, A. G. Kontos, P. S. M. Dunlop, J. W. J. Hamilton, J. A. Byrne, K. O'Shea, M. H. Entezari and D. D. Dionysiou, Appl. Catal. B Environ., 2012, 125, 331-349.

R. Kaplan, B. Erjavec, G. Dražić, J. Grdadolnik and A. Pintar, Simple synthesis of anatase/rutile/brookite

$\mathrm{TiO}<\mathrm{inf}>2<$ inf $>$ nanocomposite with superior mineralization potential for photocatalytic degradation of water pollutants, Appl. Catal. B Environ., 2016, 181, 465474.

H. Zhao, L. Liu, J. M. Andino and Y. Li, Bicrystalline TiO2 with controllable anatase-brookite phase content for enhanced $\mathrm{CO} 2$ photoreduction to fuels, J. Mater. Chem. A, 2013, 1, 8209-8216.

H. Wang, X. Gao, G. Duan, X. Yang and X. Liu, Facile preparation of anatase-brookite-rutile mixed-phase $\mathrm{N}$ doped TiO2 with high visible-light photocatalytic activity, J. Environ. Chem. Eng., 2015, 3, 603-608.

S. G. Kumar and K. S. R. K. Rao, Polymorphic phase transition among the titania crystal structures using a solution-based approach: From precursor chemistry to nucleation process, Nanoscale, 2014, 6, 11574-11632. R. Boppella, P. Basak and S. V. Manorama, Viable method for the synthesis of biphasic TiO 2 nanocrystals with tunable phase composition and enabled visible-light photocatalytic performance, ACS Appl. Mater. Interfaces, 2012, 4, 1239-1246.

T. A. Kandiel, L. Robben, A. Alkaim and D. Bahnemann, in Photochemical and Photobiological Sciences, Royal Society of Chemistry, 2013, vol. 12, pp. 602-609.

M. Monai, T. Montini and P. Fornasiero, Catalysts, 2017, 7, 304.

A. Di Paola, M. Bellardita and L. Palmisano, Catalysts, 2013, 3, 36-73.

11 Y. Zou, X. Tan, T. Yu, Y. Li, Q. Shang and W. Wang, Synthesis and photocatalytic activity of chrysanthemum-like brookite TiO2 nanostructures, Mater. Lett., 2014, 132, 182-185. $X$. Hua and Z. Lizhi, Controllable one-pot synthesis and enhanced photocatalytic acti vity of mixed-phase $\mathrm{TiO} 2$ nanocrystals with tunable brookite/rutile ratios, J. Phys. Chem. C, 2009, 113, 1785-1790.

13 A. Pottier, C. Chanéac, E. Tronc, L. Mazerolles and J. P. 
Jolivet, Synthesis of brookite TiO2 nanoparticles by thermolysis of $\mathrm{TiCl} 4$ in strongly acidic aqueous media, $\mathrm{J}$. Mater. Chem., 2001, 11, 1116-1121.

14 S. Bakardjieva, V. Stengl, L. Szatmary, J. Subrt, J. Lukac, N. Murafa, D. Niznansky, K. Cizek, J. Jirkovsky and N. Petrova, Transformation of brookite-type TiO 2 nanocrystals to rutile: Correlation between microstructure and photoactivity, J. Mater. Chem., 2006, 16, 1709-1716.

15 Y. Cao, X. Li, Z. Bian, A. Fuhr, D. Zhang and J. Zhu, Highly photocatalytic activity of brookite/rutile $\mathrm{TiO} 2$ nanocrystals with semi-embedded structure, Appl. Catal. B Environ., 2016, 180, 551-558.

16 A. Di Paola, G. Cufalo, M. Addamo, M. Bellardita, R. Campostrini, M. Ischia, R. Ceccato and L. Palmisano, Photocatalytic activity of nanocrystalline $\mathrm{TiO} 2$ (brookite, rutile and brookite-based) powders prepared by thermohydrolysis of $\mathrm{TiCl} 4$ in aqueous chloride solutions, Colloids Surfaces A Physicochem. Eng. Asp., 2008, 317, 366-376.

17 R. Asahi, T. Morikawa, T. Ohwaki, K. Aoki and Y. Taga, Visible-light photocatalysis in nitrogen-doped titanium oxides, Science (80-. )., 2001, 293, 269-271.

18 Y. Aita, M. Komatsu, S. Yin and T. Sato, Phasecompositional control and visible light photocatalytic activity of nitrogen-doped titania via solvothermal process, J. Solid State Chem., 2004, 177, 3235-3238.

19 P. V. L. A. K. Reddy, P. V. L. A. K. Reddy, K. H. Kim, M. K. Kumar, C. Manvitha and J. J. Shim, Novel approach for the synthesis of nitrogen-doped titania with variable phase composition and enhanced production of hydrogen under solar irradiation, J. Ind. Eng. Chem., 2017, 53, 253-260.

20 S. Yin, Y. Aita, M. Komatsu, J. Wang, Q. Tang and T. Sato, Synthesis of excellent visible-light responsive TiO2 - XNy photocatalyst by a homogeneous precipitationsolvothermal process, J. Mater. Chem., 2005, 15, 674-682. V. Etacheri, M. K. Seery, S. J. Hinder and S. C. Pillai, Highly visible light active $\mathrm{TiO} 2-\mathrm{xNx}$ heterojunction photocatalysts, Chem. Mater., 2010, 22, 3843-3853.

22 A. Bencini and V. Lippolis, 1,10-Phenanthroline: A versatile building block for the construction of ligands for various purposes, Coord. Chem. Rev., 2010, 254, 2096-2180. C. Sanchez, J. Livage, M. Henry and F. Babonneau, Chemical modification of alkoxide precursors, J. Non. Cryst. Solids, 1988, 100, 65-76.

24 U. Schubert, S. Tewinkel and R. Lamber, Metal complexes in inorganic matrixes. 15. 1 Coordination of metal ions by lysinate-modified titanium and zirconium alkoxides and the preparation of metal/titania and metal/zirconia nanocomposites, Chem. Mater., 1996, 8, 2047-2055. U. Schubert, N. Hiising and A. Lorenz, Hybrid InorganicOrganic Materials by Sol-Gel Processing of Organofunctional Metal Alkoxides, Chem. Mater., 1995, 7, 2010-2027.

26 K. Tomita, V. Petrykin, M. Kobayashi, M. Shiro, M. Yoshimura and M. Kakihana, A water-soluble titanium complex for the selective synthesis of nanocrystalline brookite, rutile, and anatase by a hydrothermal method,

Angew. Chemie - Int. Ed., 2006, 45, 2378-2381.

27

28
M. Kobayashi, K. Tomita, V. Petrykin, M. Yoshimura and M. Kakihana, in Journal of Materials Science, 2008, vol. 43, pp. 2158-2162.

M. Yoshizawa, M. Kobayashi, V. Petrykin, H. Kato and M. Kakihana, Insights into a selective synthesis of anatase, rutile, and brookite-type titanium dioxides by a hydrothermal treatment of titanium complexes, J. Mater. Res., 2014, 29, 90-97.

M. Rico-Santacruz, Á. E. Sepúlveda, E. Serrano, E. Lalinde, J. R. Berenguer and J. García-Martínez, Organotitanias: A versatile approach for band gap reduction in titania based materials, J. Mater. Chem. C, 2014, 2, 9497-9504.

J. Jiménez-López, N. Linares, E. Serrano and J. GarcíaMartínez, Visible-Light-Activated Black Organotitanias: How Synthetic Conditions Influence Their Structure and Photocatalytic Activity, Chempluschem, 2018, 83, 390-400. M. Rico-Santacruz, Á. E. Sepúlveda, C. Ezquerro, E. Serrano, E. Lalinde, J. R. Berenguer and J. García-Martínez, Bottomup construction of highly photoactive dye-sensitized titania using $\mathrm{Ru}(\mathrm{II})$ and $\mathrm{Ir}(\mathrm{III})$ complexes as building blocks, Appl. Catal. B Environ., 2017, 200, 93-105.

J. Kido, W. Ikeda, M. Kimura and K. Nagai, White-lightemitting organic electroluminescent device using lanthanide complexes, Japanese J. Appl. Physics, Part 2 Lett., 1996, 35, L394-L396.

C. Sun, Y. Wu, W. Zhang, N. Jiang, T. Jiu and J. Fang, Improving Efficiency by Hybrid TiO 2 Nanorods with 1,10Phenanthroline as A Cathode Buffer Layer for Inverted Organic Solar Cells, ACS Appl. Mater. Interfaces, 2014, 6, 739-744.

P. G. Sammes and G. Yahioglu, 1,10-Phenanthroline: a versatile ligand, Chem. Soc. Rev., 1994, 23, 327.

A. Kunzmann, S. Valero, Á. E. Sepúlveda, M. RicoSantacruz, E. Lalinde, J. R. Berenguer, J. García-Martínez, D. M. Guldi, E. Serrano and R. D. Costa, Hybrid Dye-Titania Nanoparticles for Superior Low-Temperature DyeSensitized Solar Cells, Adv. Energy Mater., 2018, 8, 1702583.

R. H. Wu, J. Wu, M. X. Yu and L. G. Zhu, $\mathrm{Ti}($ Phen)(OC2H5)2Cl2: A highly efficient pre-catalyst for selective oxidation of organic sulfides to sulfoxides by hydrogen peroxide, RSC Adv., 2017, 7, 44259-44264. A. A. Gribb and J. F. Banfield, Particle size effects on transformation kinetics and phase stability in nanocrystalline TiO2, Am. Mineral., 1997, 82, 717-728. H. Zhang and J. F. Banfield, Understanding polymorphic phase transformation behavior during growth of nanocrystalline aggregates: Insights from TiO2, J. Phys. Chem. B, 2000, 104, 3481-3487.

V. Gowda, R. S. Laitinen, V. V. Telkki, A. C. Larsson, O. N. Antzutkin and P. Lantto, DFT calculations in the assignment of solid-state NMR and crystal structure elucidation of a lanthanum(III) complex with dithiocarbamate and phenanthroline, Dalt. Trans., 2016, 45, 19473-19484. J. G. Yu, H. G. Yu, B. Cheng, X. J. Zhao, J. C. Yu and W. K. Ho, The Effect of Calcination Temperature on the Surface 
Microstructure and Photocatalytic Activity of TiO2 Thin Films Prepared by Liquid Phase Deposition, J. Phys. Chem. $B, 2003,107,13871-13879$.

41 T. P. Gerasimova and S. A. Katsyuba, Bipyridine and phenanthroline IR-spectral bands as indicators of metal spin state in hexacoordinated complexes of $\mathrm{Fe}(\mathrm{ii}), \mathrm{Ni}(\mathrm{ii})$ and Co(ii), Dalt. Trans., 2013, 42, 1787-1797. S. S. Singh, Infrared Spectra of 1:10 Phenanthroline and its Addition Compounds with Antimony Trichloride and Antimony Pentachloride, Zeitschrift fur Naturforsch. - Sect. A J. Phys. Sci., 1969, 24, 2015-2016.

43 A. A. Schilt and R. C. Taylor, Infra-red spectra of 1:10phenanthroline metal complexes in the rock salt region below $2000 \mathrm{~cm}$-1, J. Inorg. Nucl. Chem., 1959, 9, 211-221. M. M. Campos-Vallette, R. E. Clavijo, F. Mendizabal, W. Zamudio, R. Baraona and G. Diaz, Infrared spectrum of the bis-(1,10-phenanthroline) $\mathrm{Cu}(\mathrm{I})$ and $\mathrm{Cu}(\mathrm{II})$ perchlorate complexes, Vib. Spectrosc., 1996, 12, 37-44. D. J. Awad, F. Conrad, A. Koch, U. Schilde, A. Pöppl and P. Strauch, 1,10-Phenanthroline-dithiolate mixed ligand transition metal complexes. Synthesis, characterization and EPR spectroscopy, Inorganica Chim. Acta, 2010, 363, 14881494.

46 V. Kumar, O. M. Ntwaeaborwa, J. Holsa, D. E. Motaung and H. C. Swart, The role of oxygen and titanium related defects on the emission of TiO2:Tb3+ nano-phosphor for blue lighting applications, Opt. Mater. (Amst)., 2015, 46, 510-516.

47 C. Retamoso, N. Escalona, M. González, L. Barrientos, P. Allende-González, S. Stancovich, R. Serpell, J. L. G. Fierro and M. Lopez, Effect of particle size on the photocatalytic activity of modified rutile sand (TiO 2 ) for the discoloration of methylene blue in water, J. Photochem. Photobiol. A Chem., 2019, 378, 136-141.

48 M. J. Jackman, A. G. Thomas and C. Muryn, Photoelectron spectroscopy study of stoichiometric and reduced anatase TiO<inf $>2</$ inf $>(101)$ surfaces: The effect of subsurface defects on water adsorption at near-ambient pressures, $J$. Phys. Chem. C, 2015, 119, 13682-13690.

$49 \mathrm{X}$. Chen and C. Burda, Photoelectron spectroscopic investigation of nitrogen-doped titania nanoparticles, J. Phys. Chem. B, 2004, 108, 15446-15449.

50 P. Zhu, L. Xie, M. Duan, M. Hu, J. Xu and R. Wang, Fabrication and Characterization of N-TiO2/C/ATP Composite with Enhanced Visible-Light Photocatalytic Performance for the Degradation of Polyacrylamide in Wastewater, ChemistrySelect, 2020, 5, 5349-5359.

P. Gayathri and A. Senthil Kumar, Electrochemical behavior of the 1,10-phenanthroline ligand on a multiwalled carbon nanotube surface and its relevant electrochemistry for selective recognition of copper ion and hydrogen peroxide sensing, Langmuir, 2014, 30, 10513-10521. S. Challagulla, K. Tarafder, R. Ganesan and S. Roy, Structure sensitive photocatalytic reduction of nitroarenes over TiO 2, Sci. Rep., , DOI:10.1038/s41598-017-08599-2.

53 M. Rezaee, S. M. Mousavi Khoie and K. H. Liu, The role of brookite in mechanical activation of anatase-to-rutile transformation of nanocrystalline TiO2: An XRD and Raman spectroscopy investigation, CrystEngComm, 2011, 13, 5055-5061.

D. O. Scanlon, C. W. Dunnill, J. Buckeridge, S. A. Shevlin, A. J. Logsdail, S. M. Woodley, C. R. A. Catlow, M. J. Powell, R. G. Palgrave, I. P. Parkin, G. W. Watson, T. W. Keal, P. Sherwood, A. Walsh and A. A. Sokol, Band alignment of rutile and anatase TiO2, Nat. Mater., 2013, 12, 798-801. S. Xie, Q. Zhang, G. Liu and Y. Wang, Photocatalytic and photoelectrocatalytic reduction of $\mathrm{CO} 2$ using heterogeneous catalysts with controlled nanostructures, Chem. Commun., 2016, 52, 35-59.

C. Maheu, L. Cardenas, E. Puzenat, P. Afanasiev and C. Geantet, UPS and UV spectroscopies combined to position the energy levels of TiO2 anatase and rutile nanopowders, Phys. Chem. Chem. Phys., 2018, 20, 25629-25637. Y. Nosaka and A. Y. Nosaka, J. Phys. Chem. Lett., 2016, 7, 431-434.

J. Chen, M. Guan, X. Zhang and X. Gong, Insights into a rutile/brookite homojunction of titanium dioxide: Separated reactive sites and boosted photocatalytic activity, RSC Adv., 2019, 9, 36615-36620.

A. Di Paola, M. Bellardita, L. Palmisano and F. Parrino, Junction Effect on the Photocatalytic Activity of MixedPhase TiO 2 Nanoparticles, ECS Trans., 2019, 25, 29-35. H. Cheng, J. Ma, Z. Zhao and L. Qi, Hydrothermal Preparation of Uniform Nanosize Rutile and Anatase Particles, Chem. Mater., 1995, 7, 663-671.

K. Maeda, T. Takata, M. Hara, N. Saito, Y. Inoue, H. Kobayashi and K. Domen, GaN:ZnO solid solution as a photocatalyst for visible-light-driven overall water splitting, J. Am. Chem. Soc., 2005, 127, 8286-8287.

H. Kisch and D. Bahnemann, J. Phys. Chem. Lett., 2015, 6, 1907-1910.

J. M. Buriak, P. V. Kamat and K. S. Schanze, ACS Appl. Mater. Interfaces, 2014, 6, 11815-11816.

S. K. Ray, D. Dhakal, Y. K. Kshetri and S. W. Lee, Cu- $\alpha-$ $\mathrm{NiMoO} 4$ photocatalyst for degradation of Methylene blue with pathways and antibacterial performance, $J$. Photochem. Photobiol. A Chem., 2017, 348, 18-32. Z. He, C. Sun, S. Yang, Y. Ding, H. He and Z. Wang, Photocatalytic degradation of rhodamine B by Bi2WO6 with electron accepting agent under microwave irradiation: Mechanism and pathway, J. Hazard. Mater., 2009, 162, 1477-1486.

B. R. V. Ferreira, D. N. Correa, M. N. Eberlin and P. H. Vendramini, Fragmentation reactions of rhodamine $B$ and $6 \mathrm{G}$ as revealed by high accuracy orbitrap tandem mass spectrometry, J. Braz. Chem. Soc., 2017, 28, 136-142. T. Rasheed, M. Bilal, H. M. N. Iqbal, H. Hu and X. Zhang, Reaction Mechanism and Degradation Pathway of Rhodamine 6G by Photocatalytic Treatment, Water. Air. Soil Pollut., 2017, 228, 1-10.

S. Rajoriya, S. Bargole and V. K. Saharan, Degradation of a cationic dye (Rhodamine 6G) using hydrodynamic cavitation coupled with other oxidative agents: Reaction mechanism and pathway, Ultrason. Sonochem., 2017, 34, 
183-194.

69 C. Yang, W. Dong, G. Cui, Y. Zhao, X. Shi, X. Xia, B. Tang and $W$. Wang, Highly efficient photocatalytic degradation of methylene blue by P2ABSA-modified TiO2 nanocomposite due to the photosensitization synergetic effect of $\mathrm{TiO} 2$ and P2ABSA, RSC Adv., 2017, 7, 23699-23708.

70 Q. Wang, S. Tian and P. Ning, Degradation mechanism of methylene blue in a heterogeneous fenton-like reaction catalyzed by ferrocene, Ind. Eng. Chem. Res., 2014, 53, 643-649.

71 M. Pelaez, P. Falaras, V. Likodimos, K. O'Shea, A. A. de la Cruz, P. S. M. Dunlop, J. A. Byrne and D. D. Dionysiou, Use of selected scavengers for the determination of NF-TiO2 reactive oxygen species during the degradation of microcystin-LR under visible light irradiation, J. Mol. Catal. A Chem., 2016, 425, 183-189.

72 J. Schneider and D. W. Bahnemann, J. Phys. Chem. Lett., 2013, 4, 3479-3483.

73 S. Rengaraj and X. Z. Li, Enhanced photocatalytic reduction reaction over $\mathrm{Bi} 3+-\mathrm{TiO} 2$ nanoparticles in presence of formic acid as a hole scavenger, Chemosphere, 2007, 66, 930-938.

74 W. Jones, D. J. Martin, A. Caravaca, A. M. Beale, M. Bowker, T. Maschmeyer, G. Hartley and A. Masters, A comparison of photocatalytic reforming reactions of methanol and triethanolamine with Pd supported on titania and graphitic carbon nitride, Appl. Catal. B Environ., 2019, 240, 373-379.

75 J. Rodríguez-López, A. Minguzzi and A. J. Bard, Reaction of Various Reductants with Oxide Films on Pt Electrodes As Studied by the Surface Interrogation Mode of Scanning Electrochemical Microscopy (SI-SECM): Possible Validity of a Marcus Relationship, , DOI:10.1021/jp107259h.

76 C. A. Parker and C. G. Hatchard, in Journal of Physical Chemistry, American Chemical Society, 1959, vol. 63, pp. 22-26.

77 C. G. H. Atchard, A new sensitive chemical actinometer - II. Potassium ferrioxalate as a standard chemical actinometer, Proc. R. Soc. London. Ser. A. Math. Phys. Sci., 1956, 235, 518-536.

78 L. Sun and J. R. Bolton, Determination of the quantum yield for the photochemical generation of hydroxyl radicals in TiO2 suspensions, J. Phys. Chem., 1996, 100, 4127-4134. 